\title{
Aesthetics and Politics of Poetry written in Tribal Languages of Kerala
}

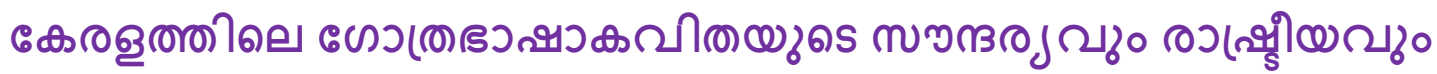

\section{R. Chandrabose ${ }^{a, *}$}

a Department of Malayalam, Central University of Kerala, Kasaragod, Kerala, India

*Corresponding author Email: bosebosechandra@gmail.com

DOI: https://doi.org/10.54392/ijmrd2144

Received 13-10-2021; Accepted 03-12-2021; Published 09-12-2021

Abstract: Poems written in Tribal languages are a notable presence in contemporary Malayalam poetry. As there is no script for those endangered tribal languages, they are written in Malayalam script. They are being translated into Malayalam. These poems become a declaration of the aboriginal community and of the aesthetics that obscure mainstream aesthetic concept. Tribal communities in Kerala lives in the forest areas of Idukki, Wayanad, Palakkad, Kasaragod, Trissur, Cochin, Trivandrum and Kollam districts. These marginalized people are facing a crisis of survival. The neglect of the main stream society and the Government and the destruction of the habitat have made their lives miserable. Indigenous tribal languages are endangered. It is in this context that the new generation of educated Adivasis seek to document their survival problem through poetry in the tribal language itself. Poems are written in tribal languages such as Irula, Rawla, Malavettuva, Paniya, Mavila and Muthuvan appearing in social media and in print and book form, they symbolize a different sensibility. The aim of this paper is to findout the political attitudes, aesthetic concepts and features of languages of the aboriginal community by studying these poems.

Keywords: Tribes, Adivasi, Eco-aesthetics, Tribal language, Endangered language, Nature images, Irula, Rawla, Malavettuva, Paniya, Mavila, Tulu, Dravidian language

Subject Specialization: Malayalam

\section{About the Author}

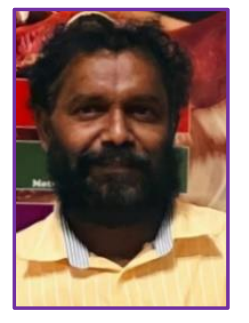

Dr.R. Chandrabose, working as Assistant Professor in the Department of Malayalam under School of languages and comparative literature, Central University of Kerala, Kasaragod. Dr.R.Chandrabose authored 30 Research papers and four Books in Malayalam.

৫ாவாவ०

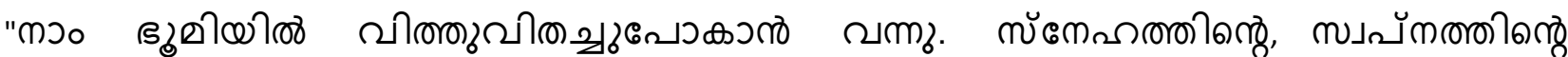

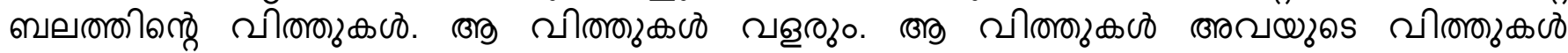

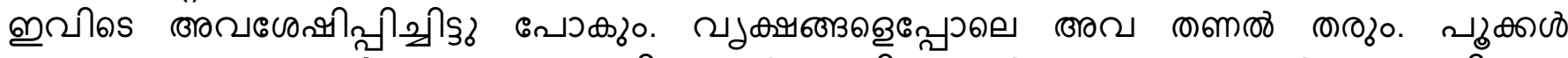

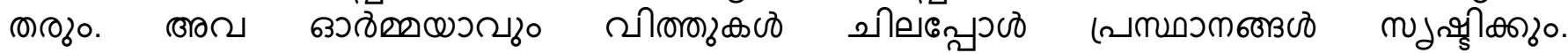

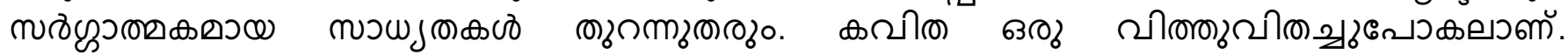

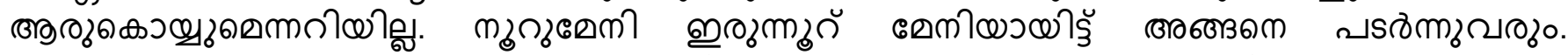

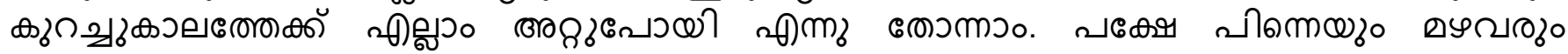

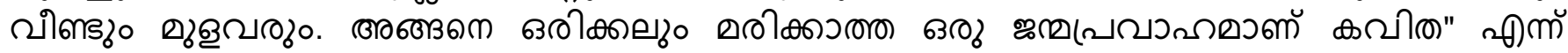

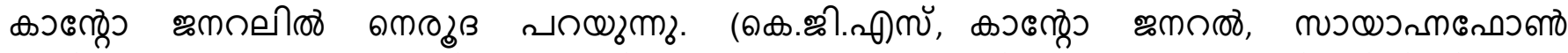

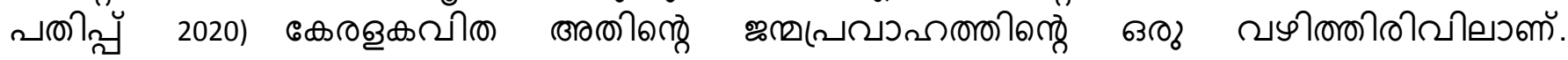




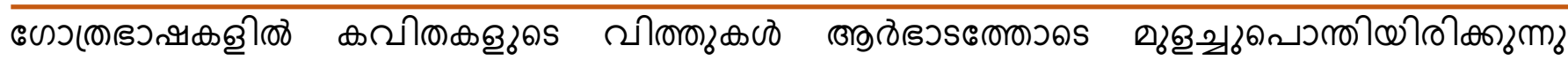

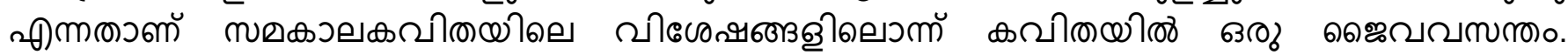

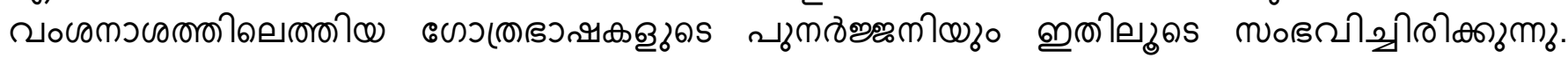

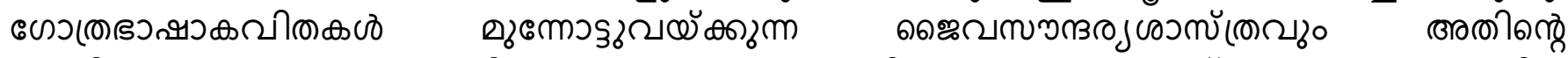

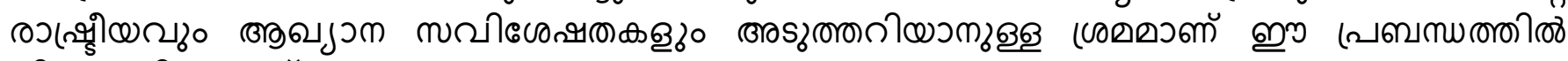

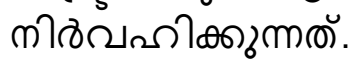

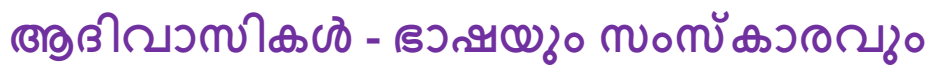

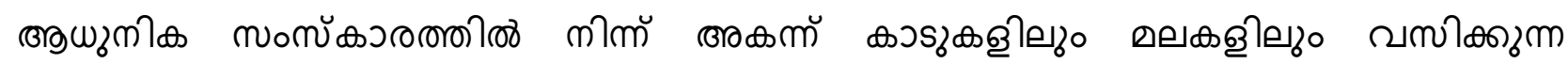

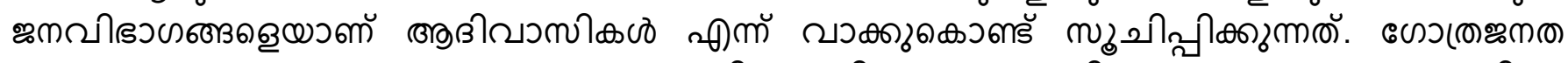

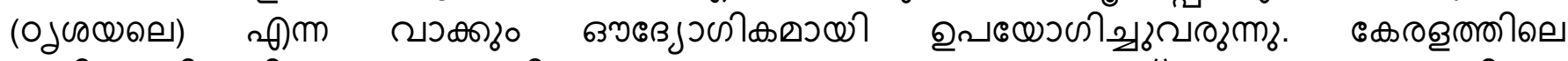

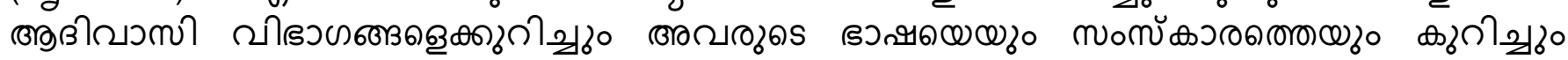

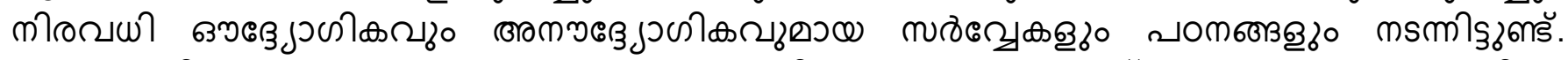

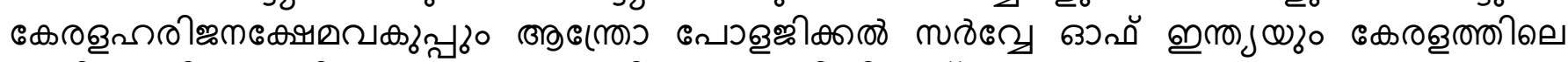

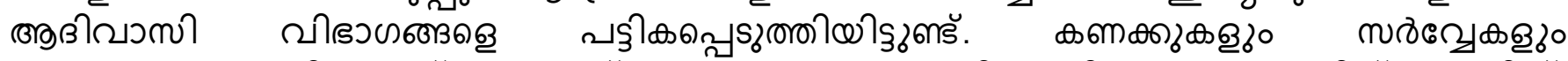
ோவ

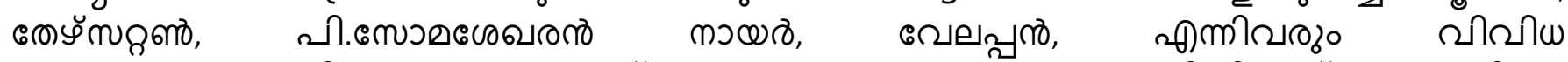

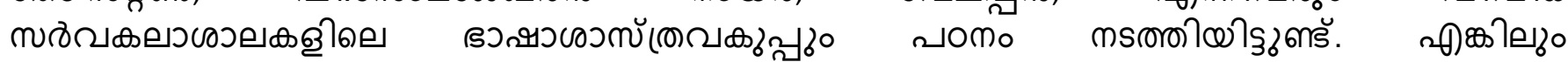

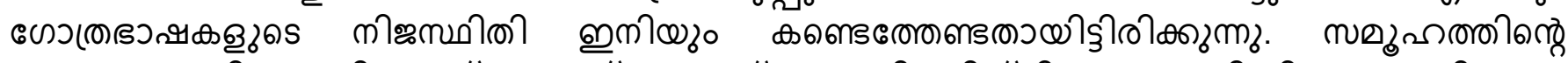

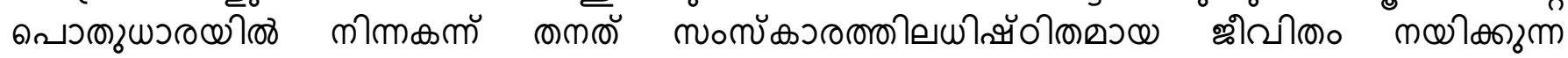

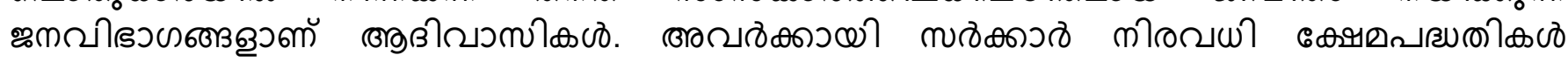

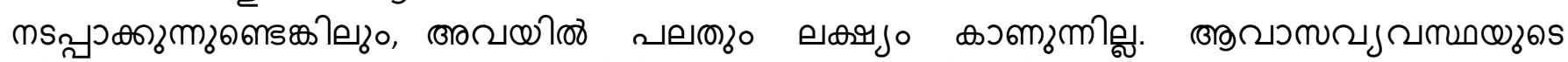

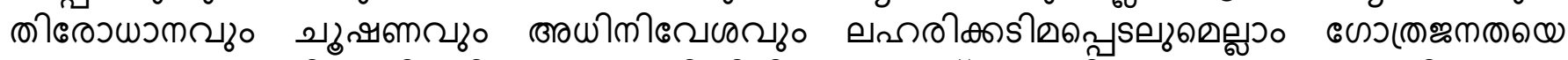

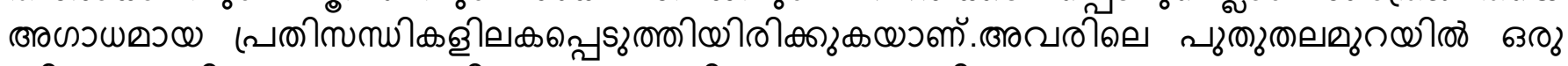

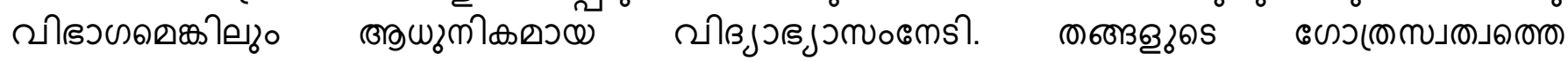

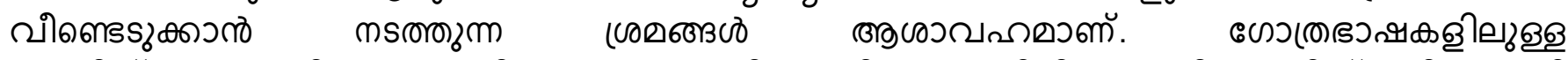
ஐூ लीभ̆

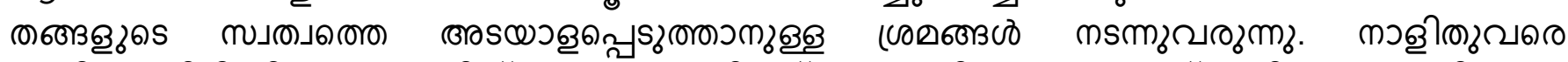

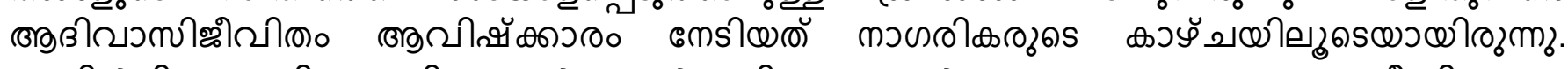

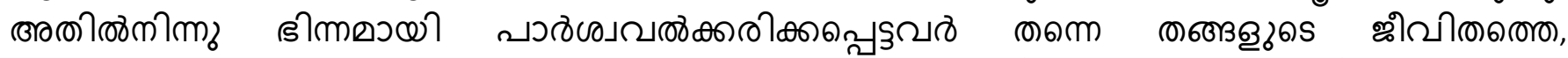

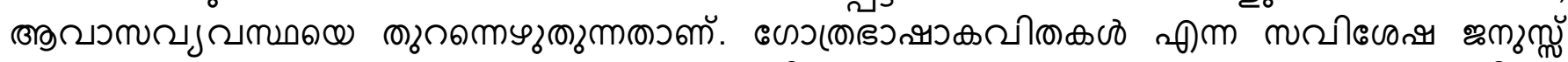

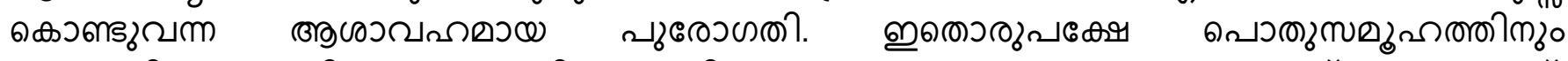

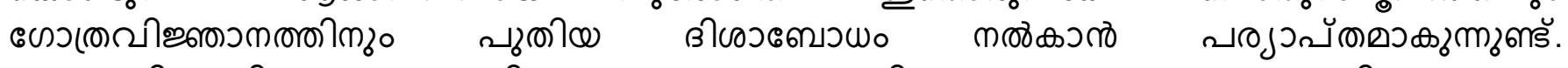

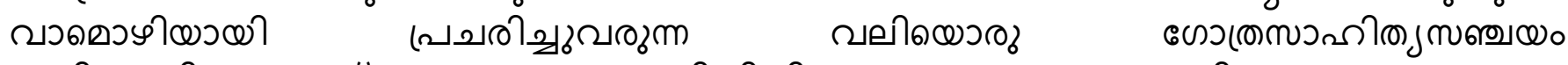

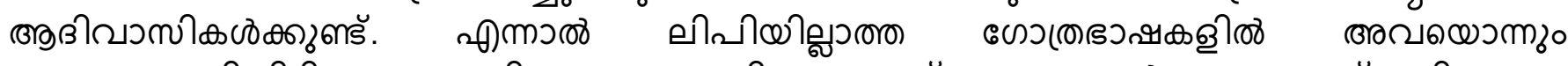

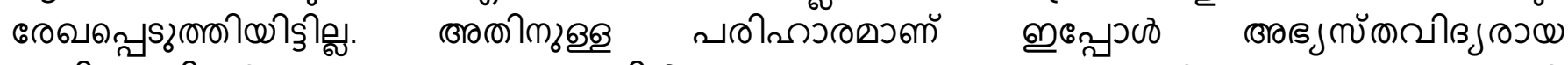

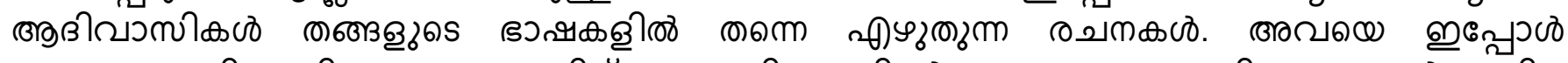

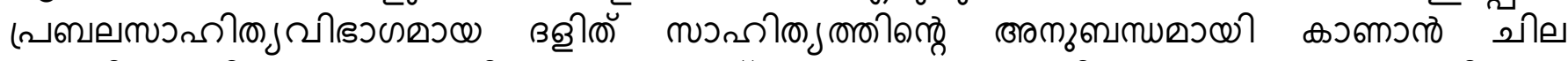

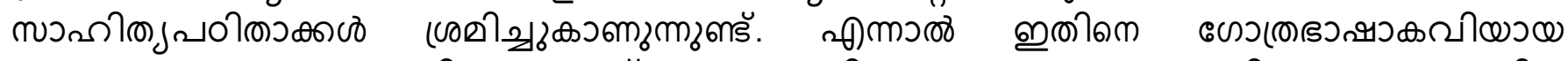

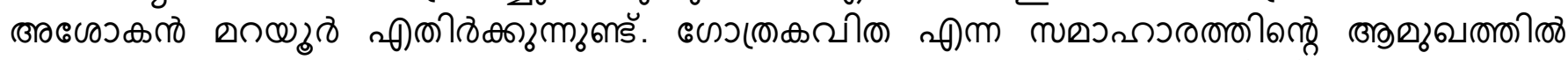

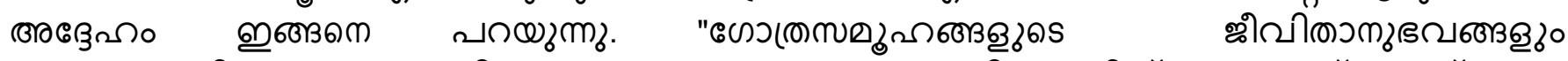

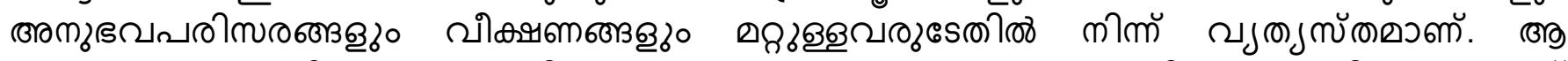

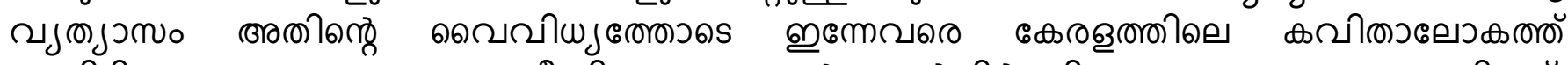

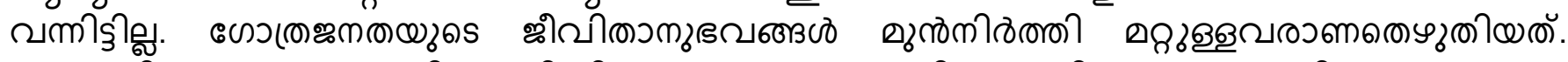

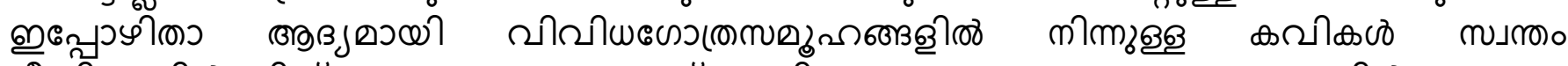

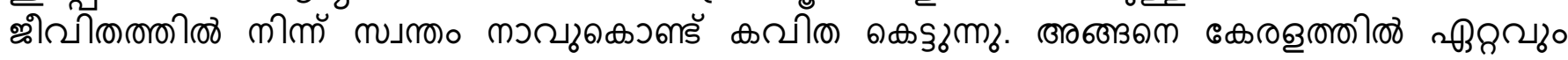




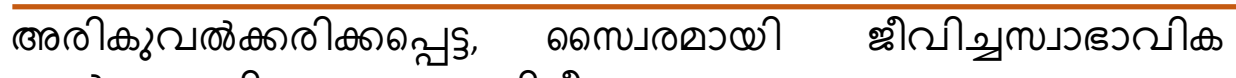

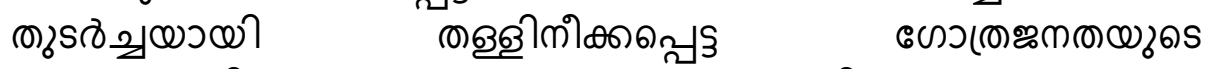

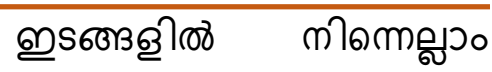

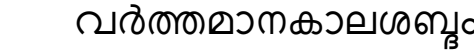

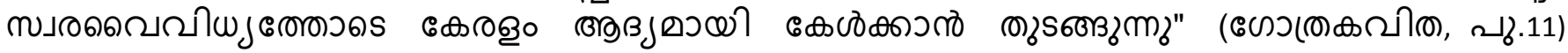

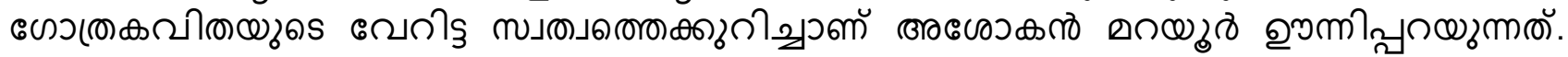

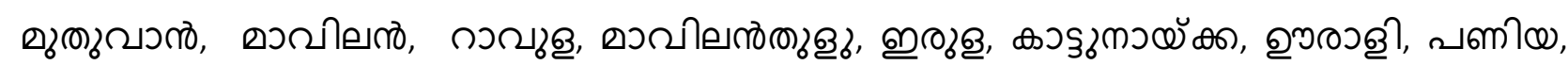

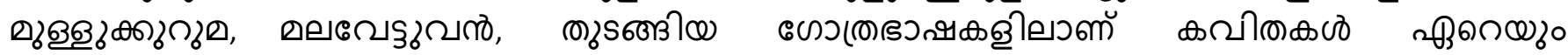

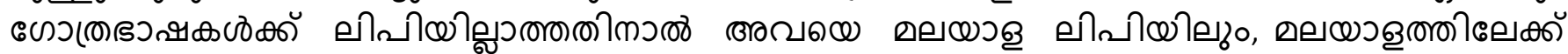

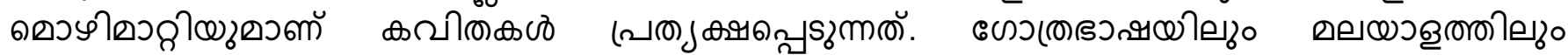

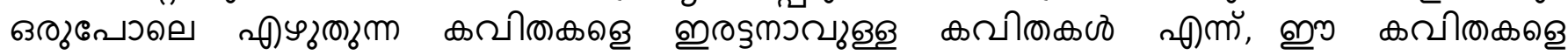

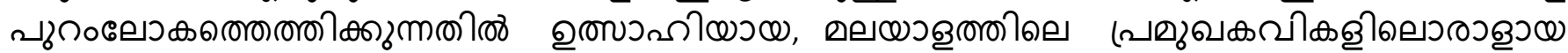

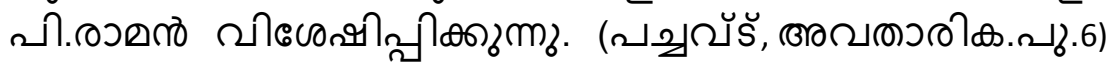

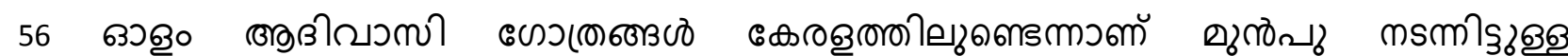

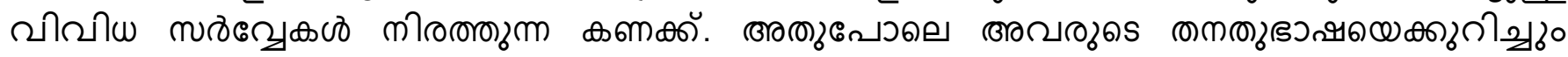

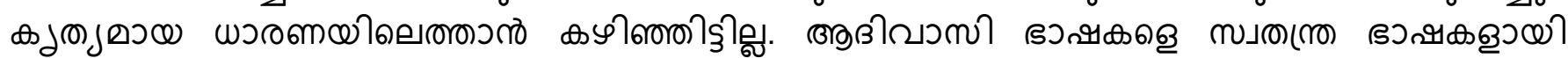

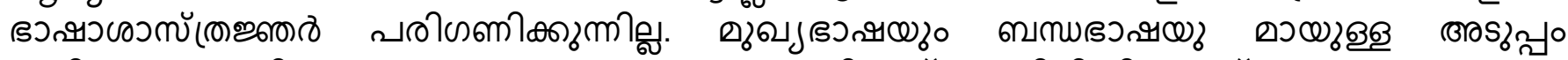

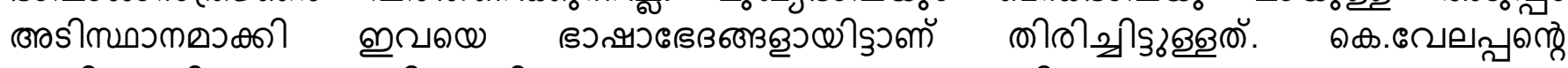

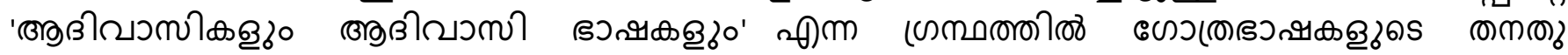

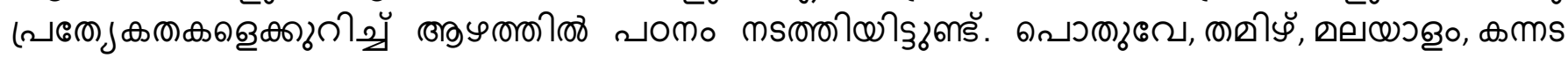

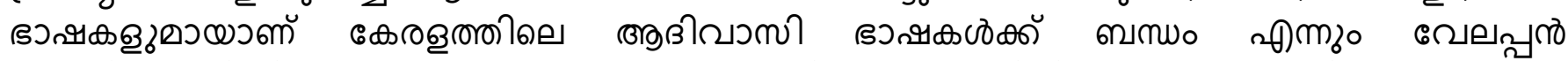

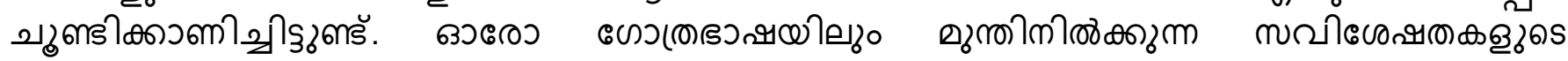

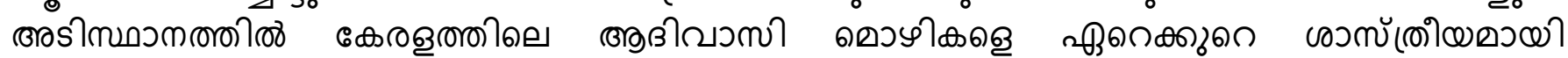

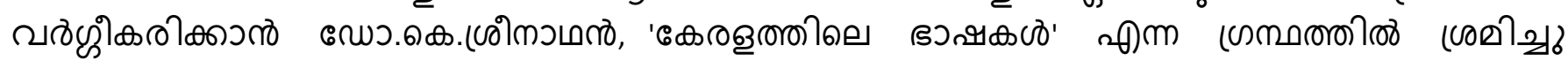

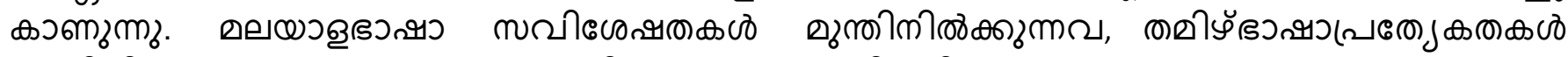

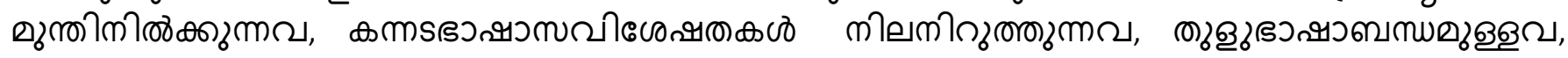

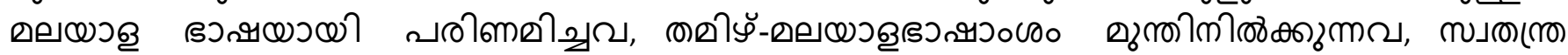

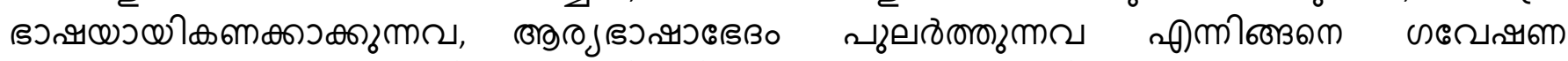

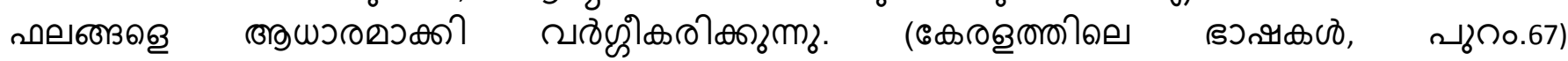

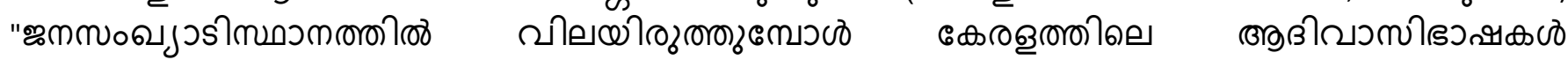

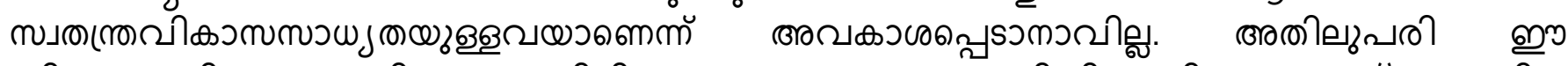

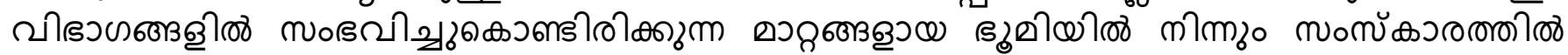

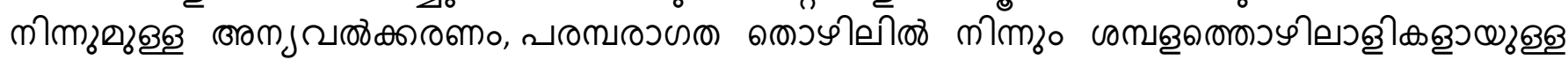

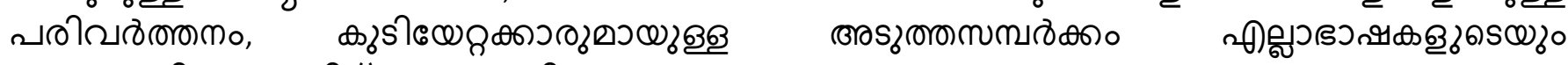

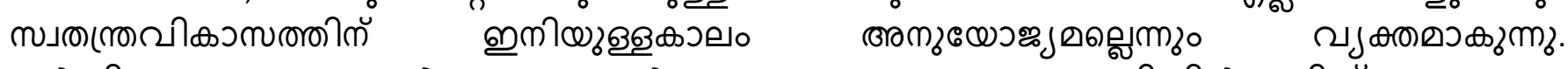

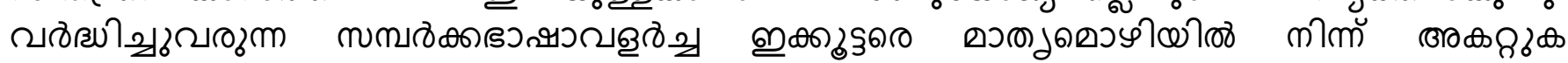

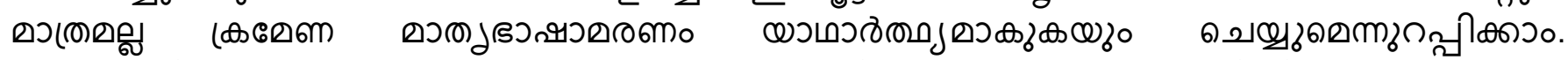

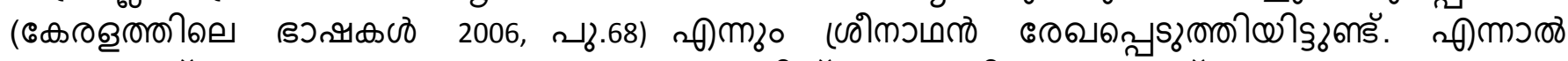

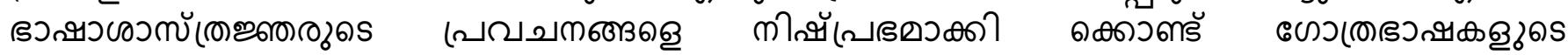

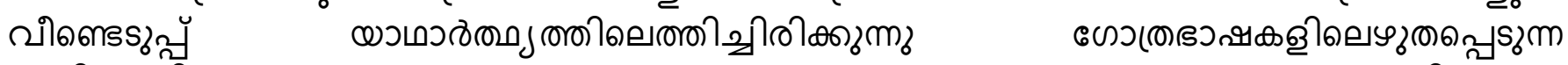

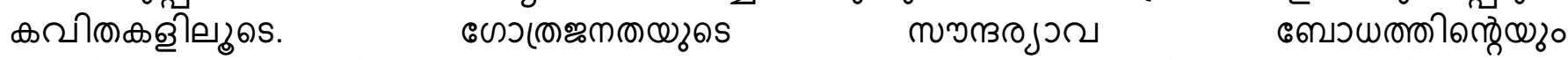

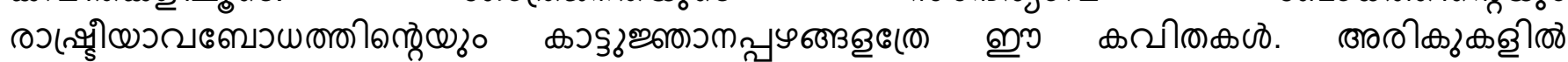

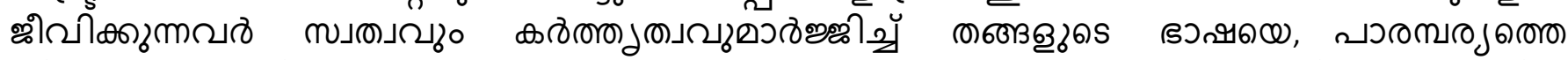

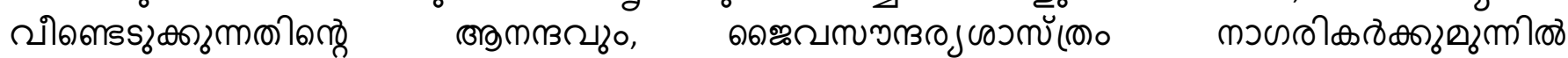

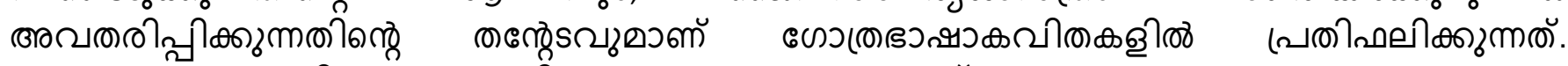

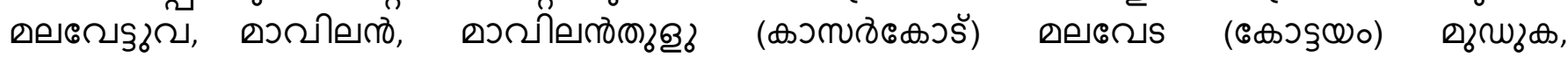

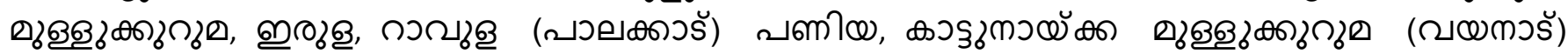

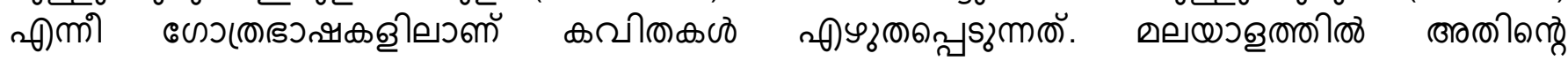




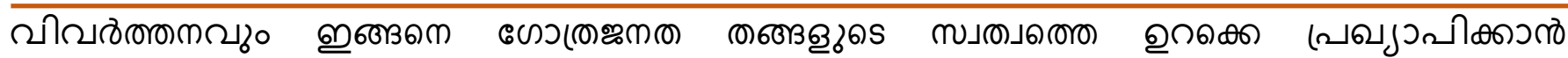

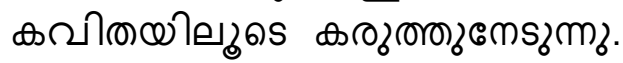

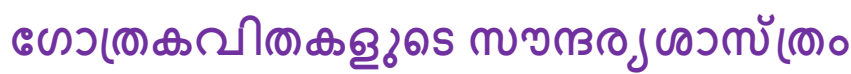

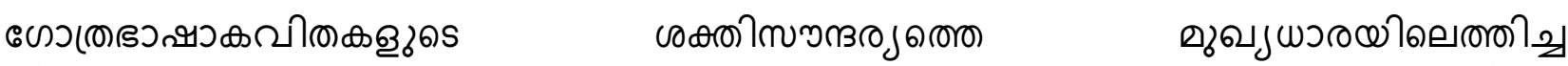

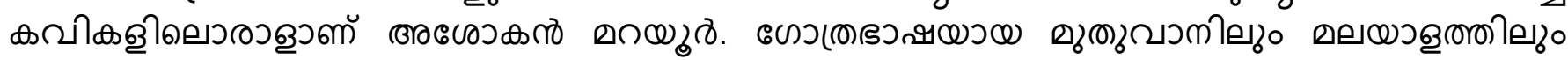

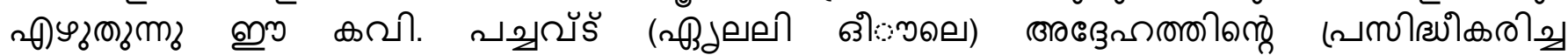

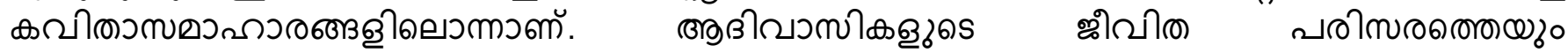

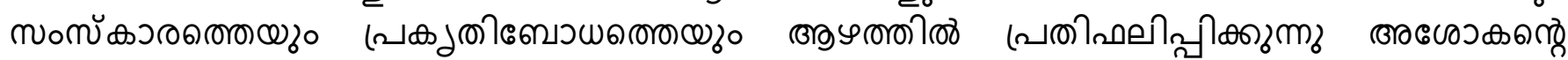

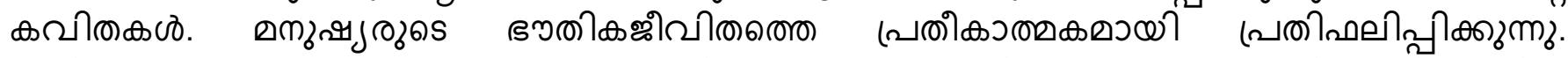

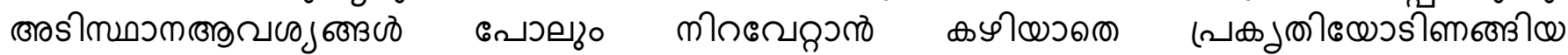

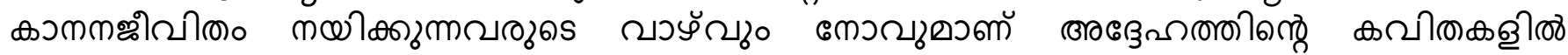

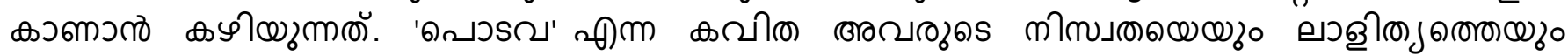

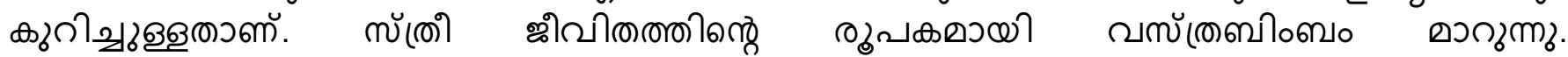

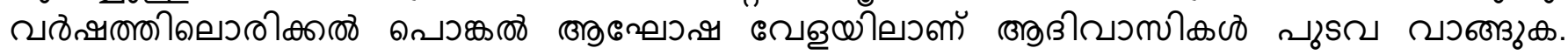

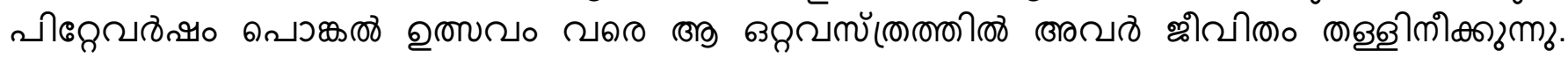

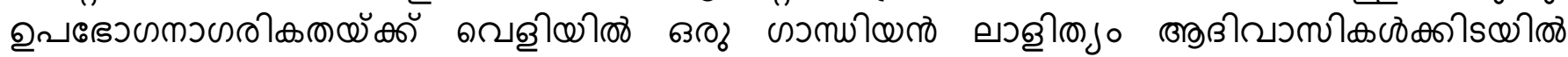

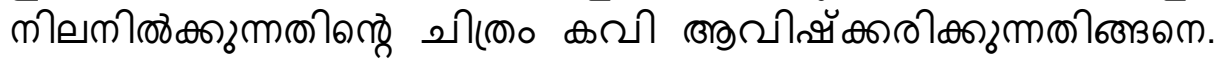

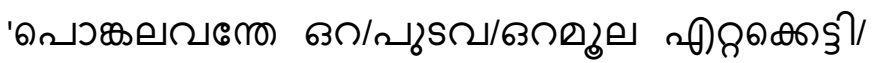

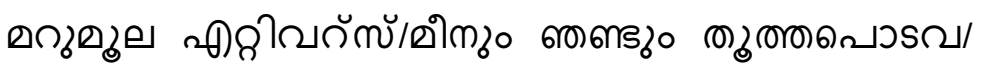

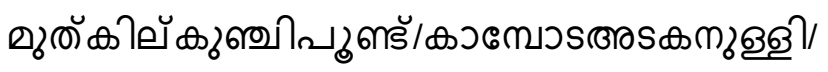

๑ெ

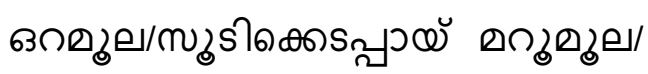

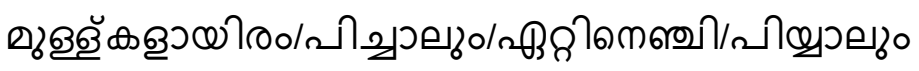

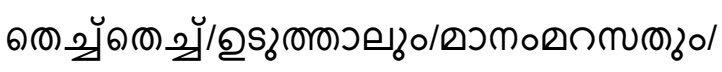

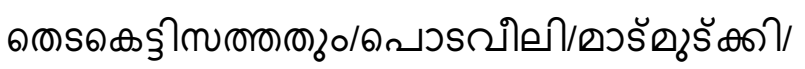

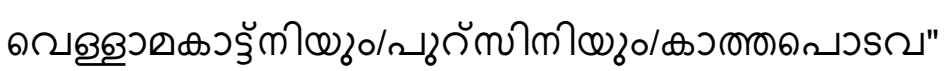

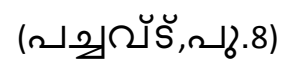

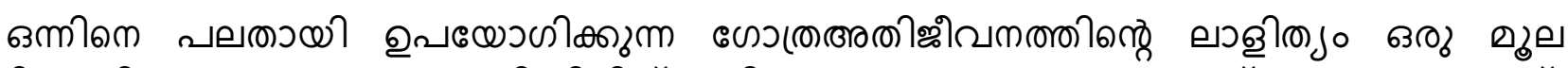

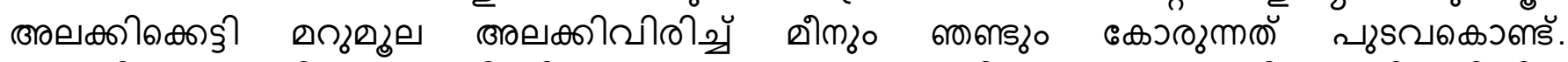

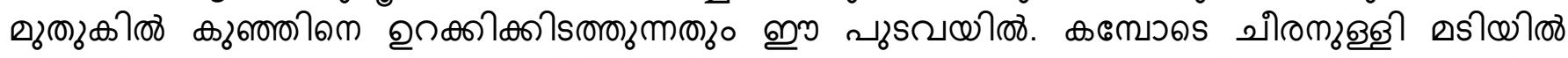

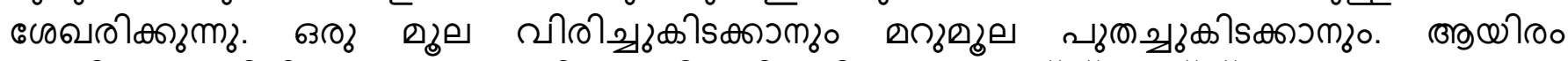

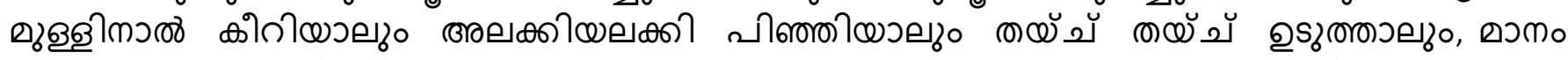

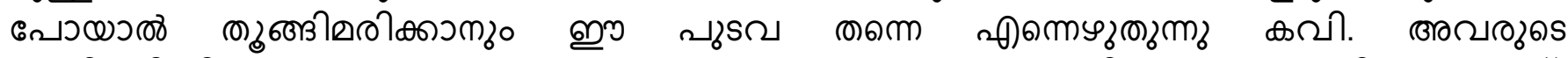

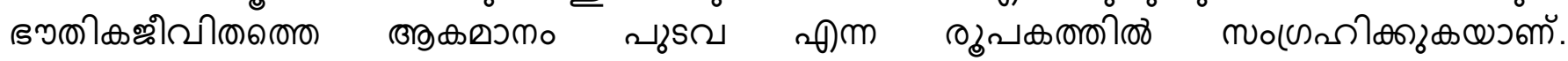

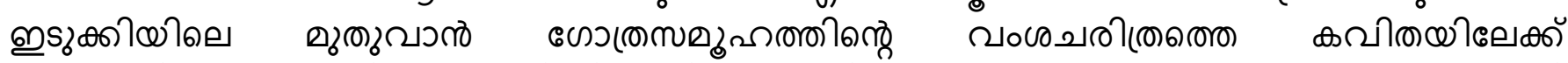

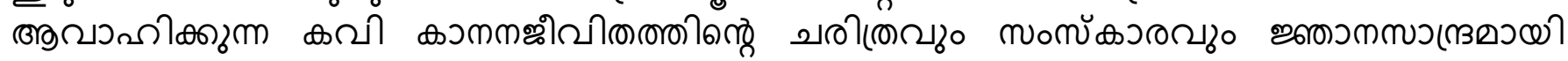

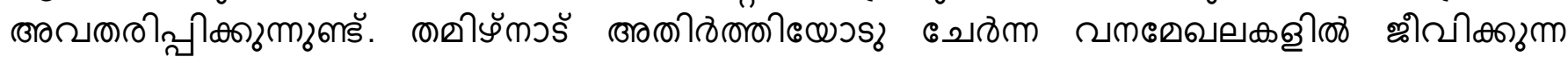

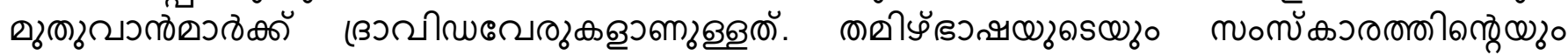

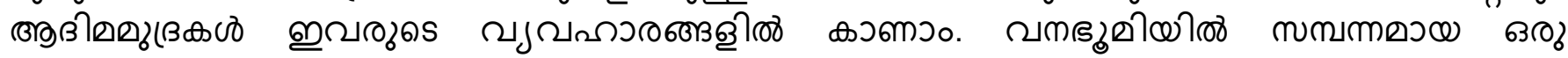

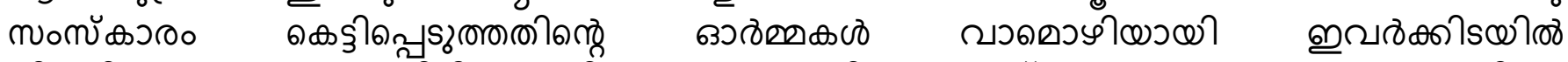

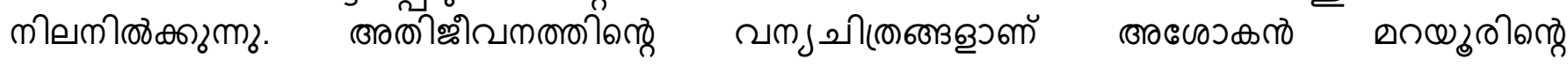




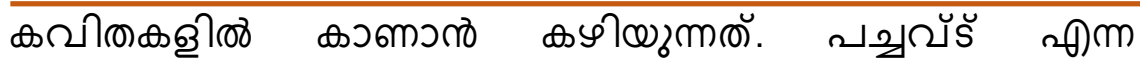

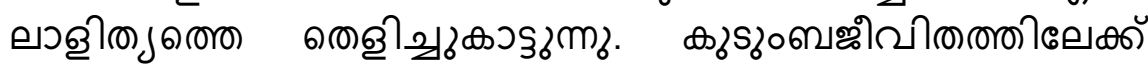

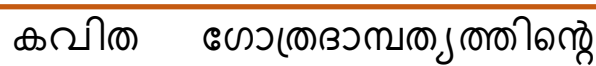

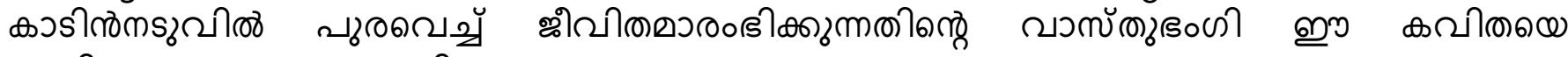

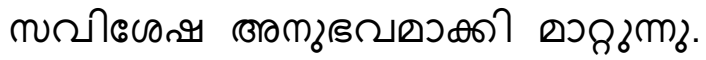

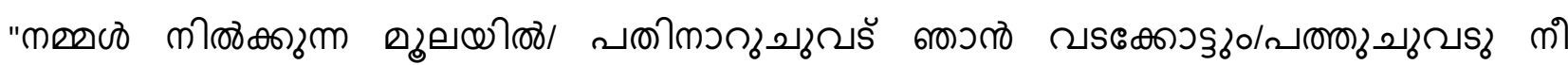

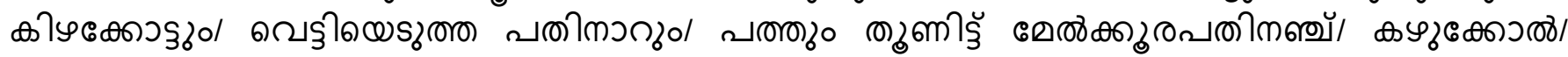

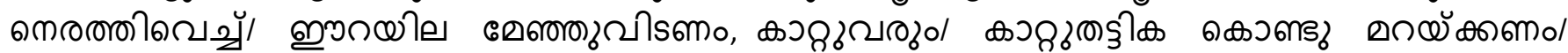

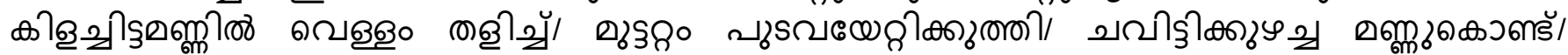

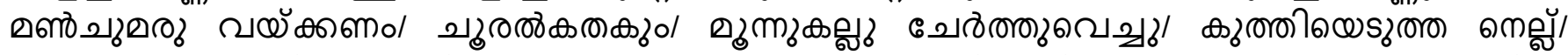

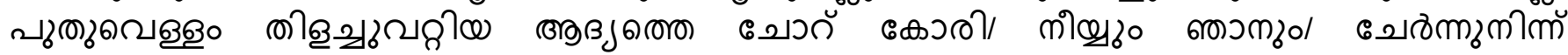

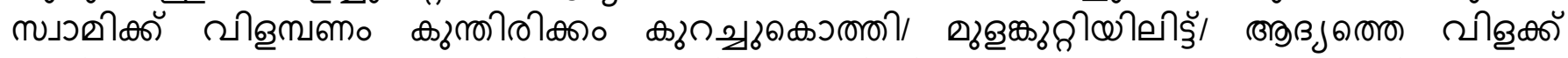

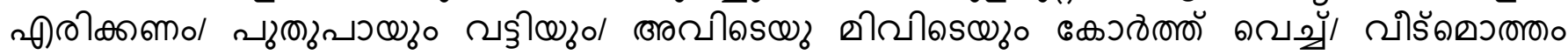

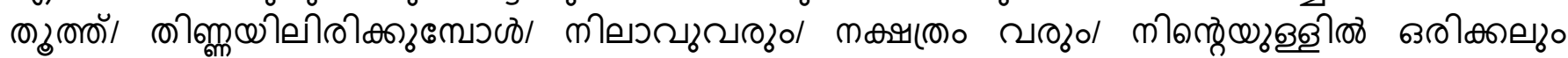

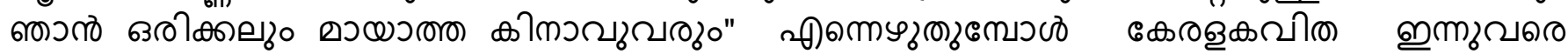

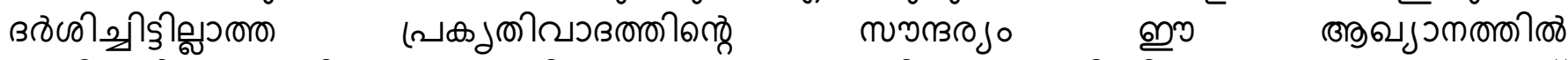

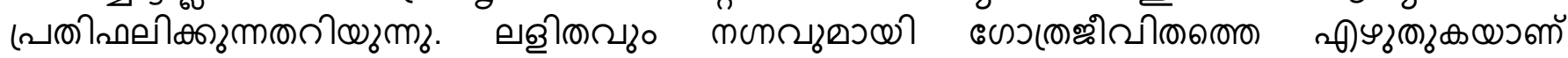

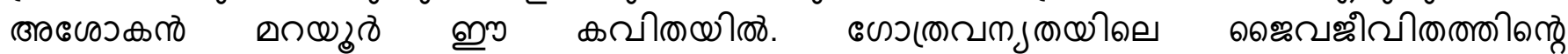

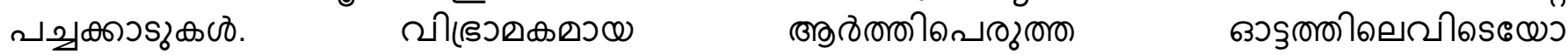

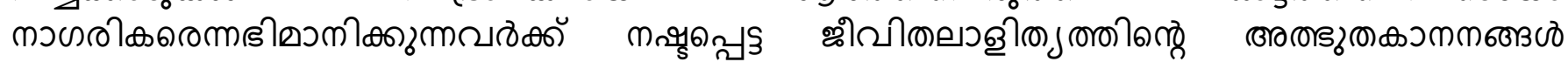

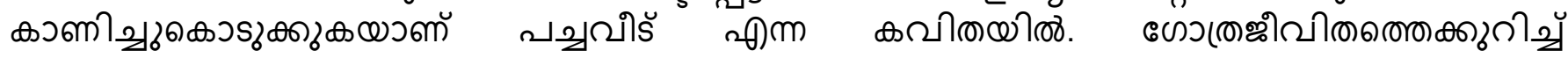

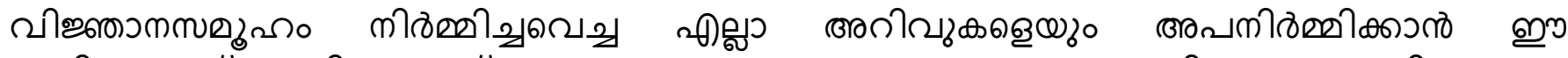

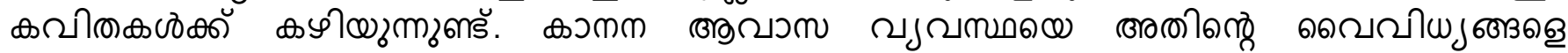

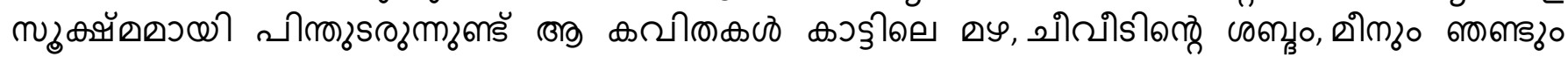

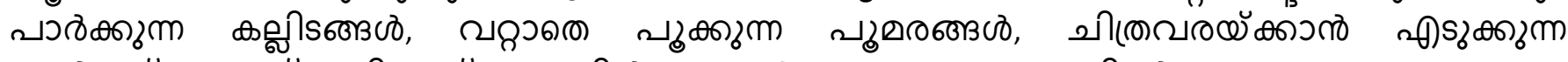

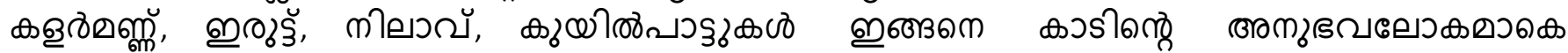

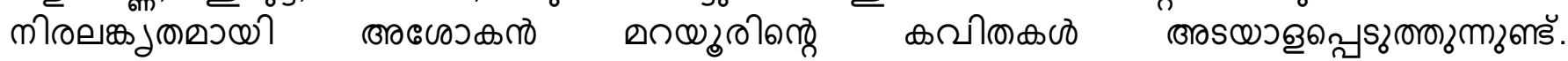

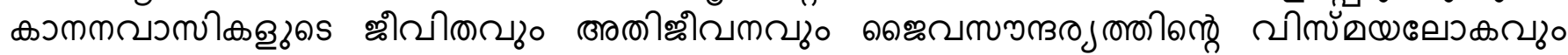

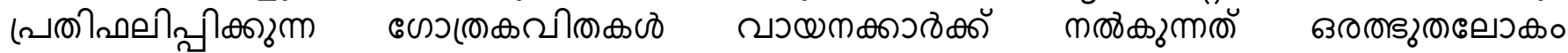
கையம்ஸॅ.

बुलुखगत

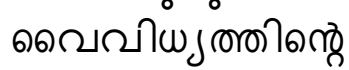
Bमण

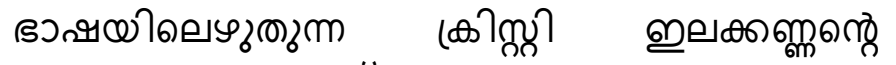
(

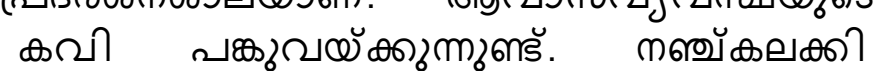

கவीळைन

๑ெஜவ

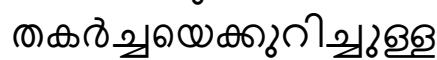

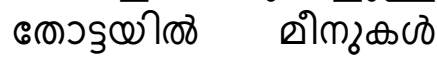

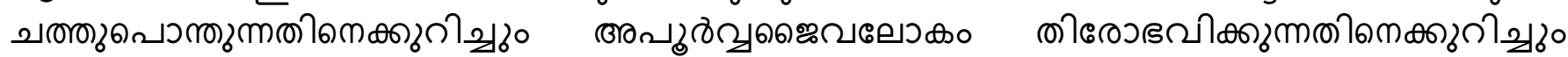

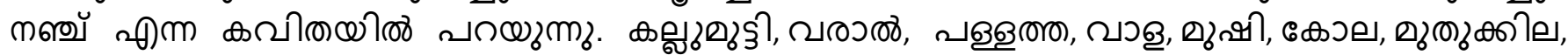

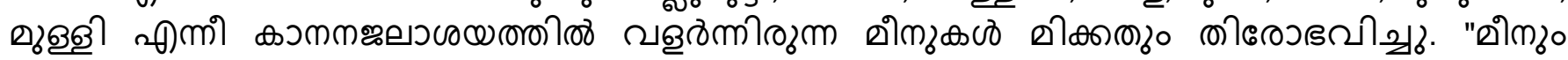

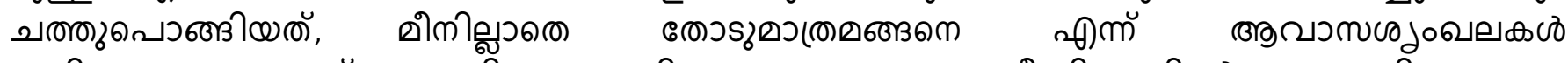

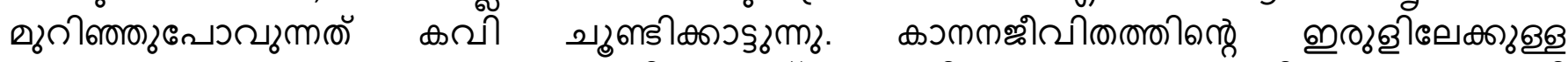

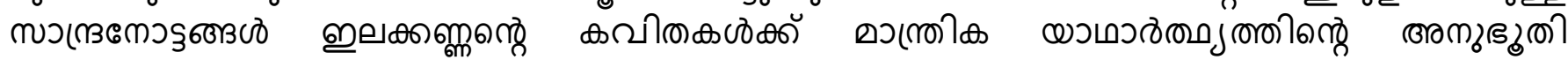

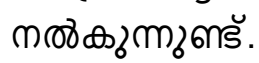

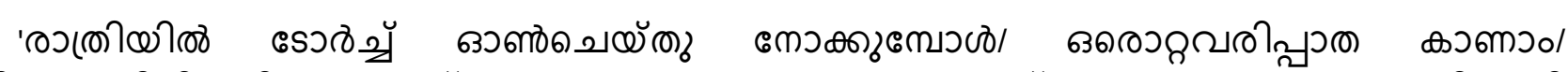

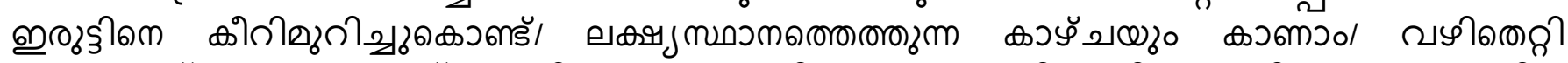

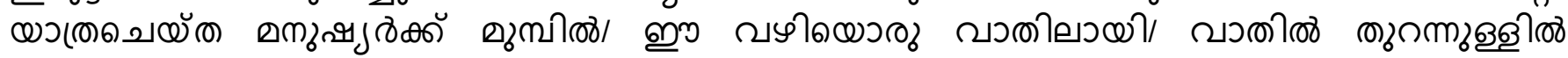

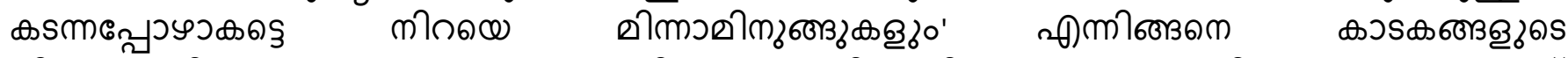

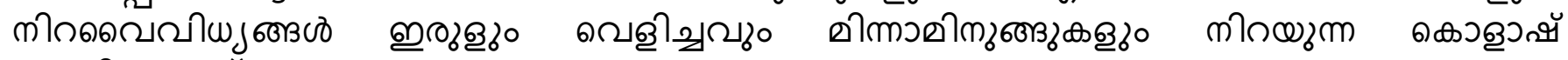

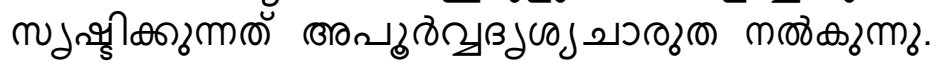




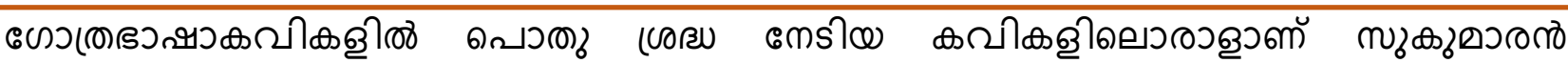

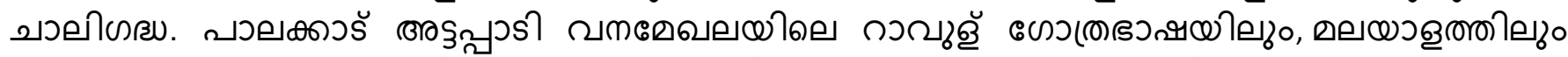

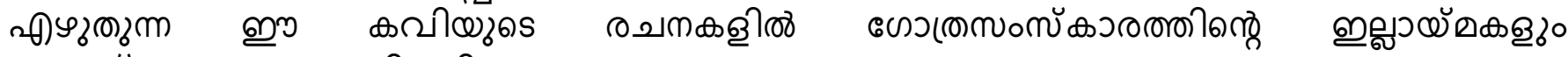

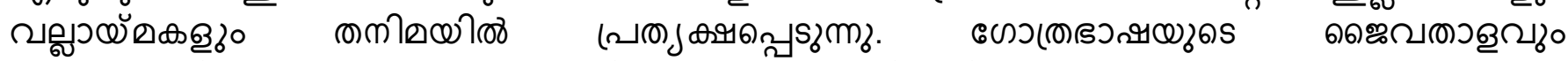

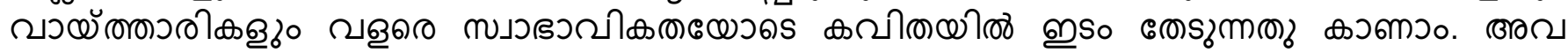

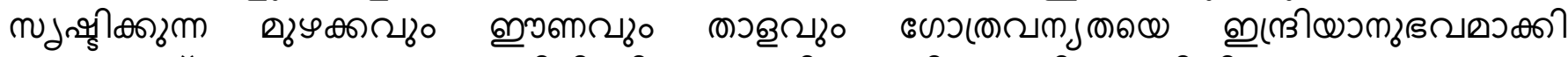

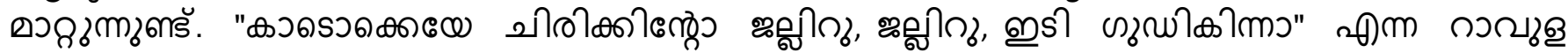

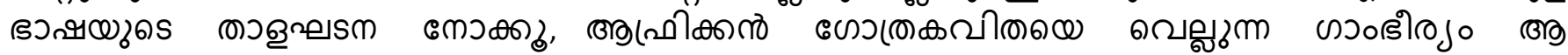

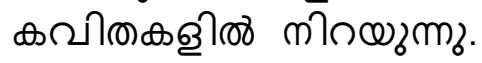

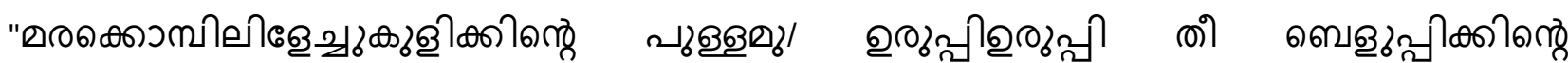

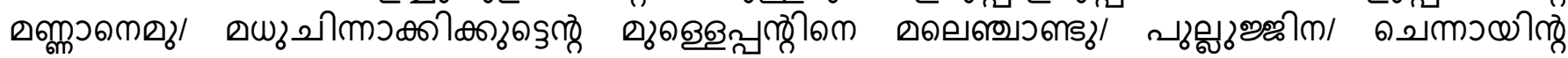

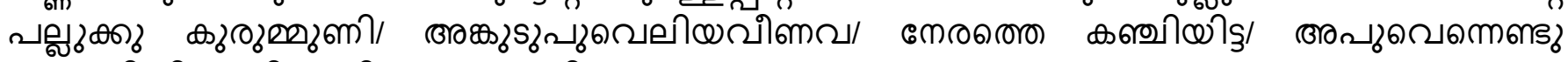

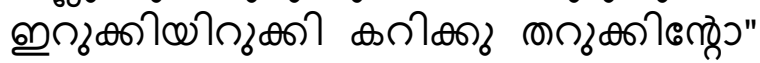

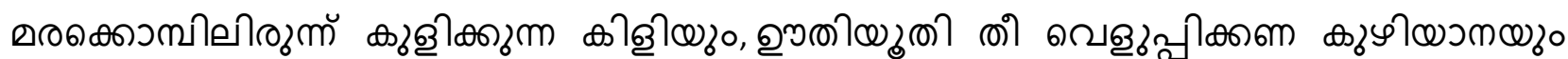

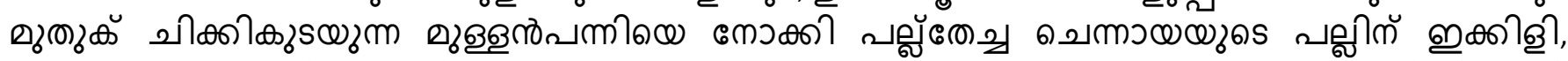

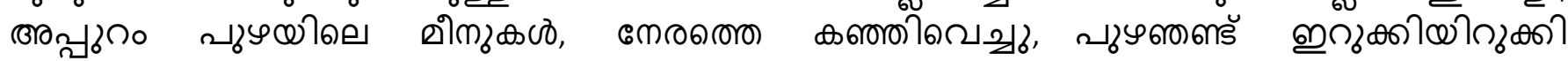

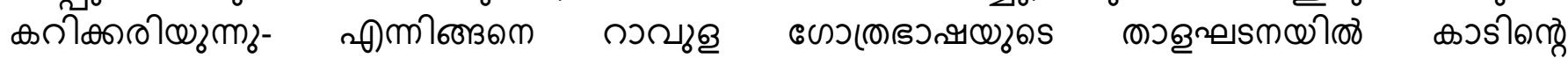

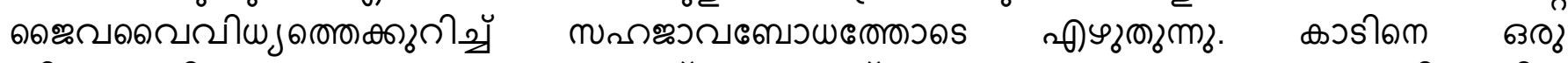

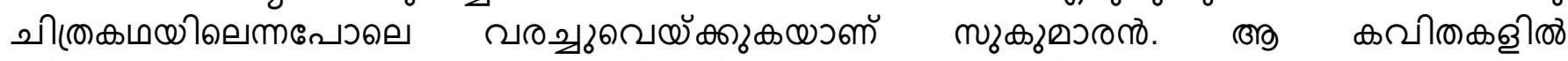

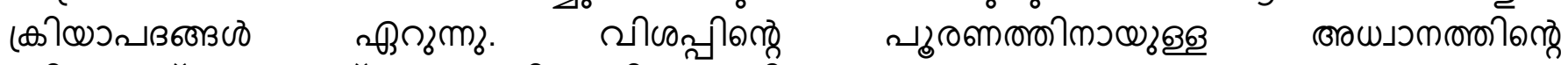

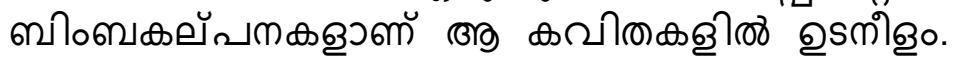

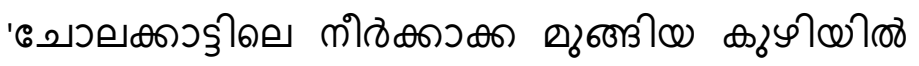

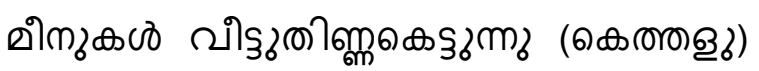

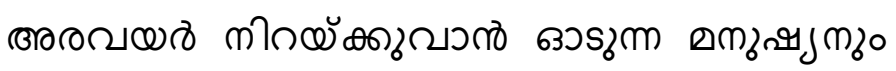

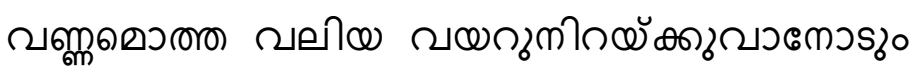

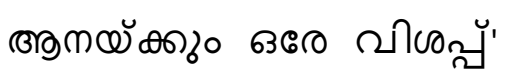

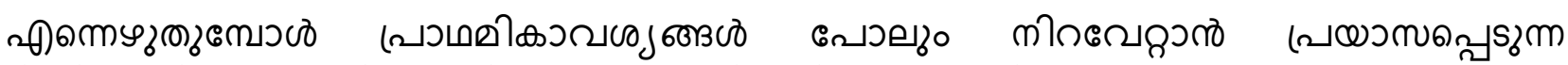

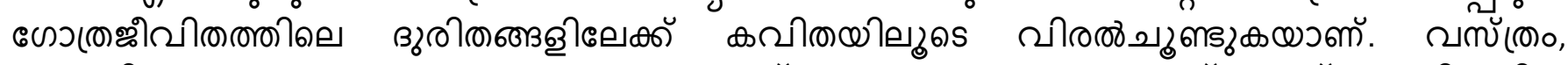

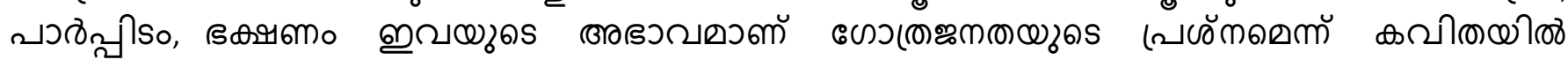

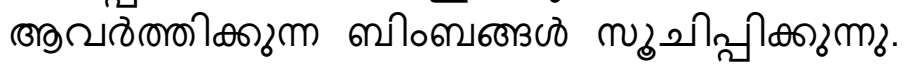

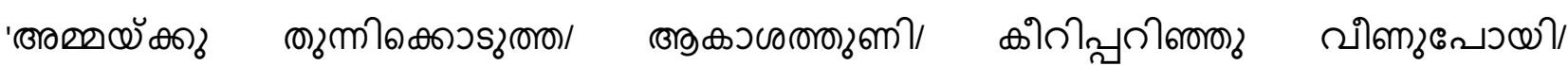

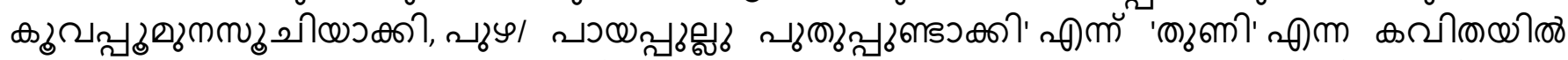

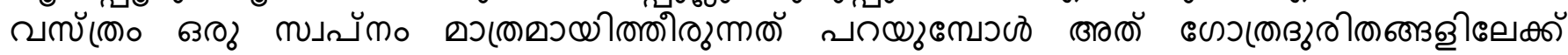

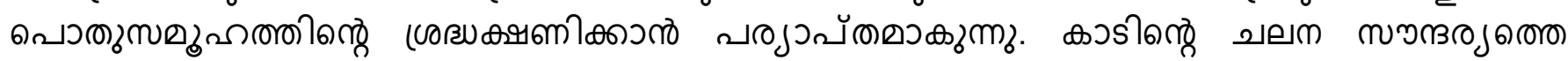

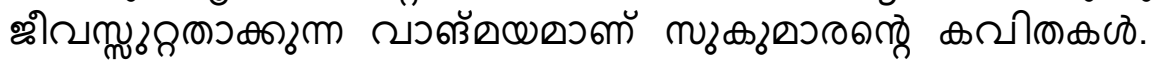

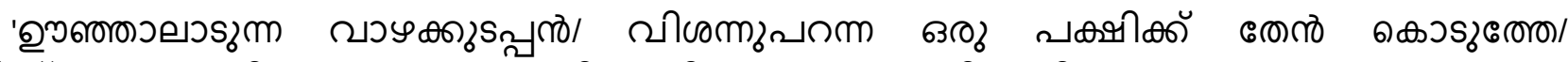

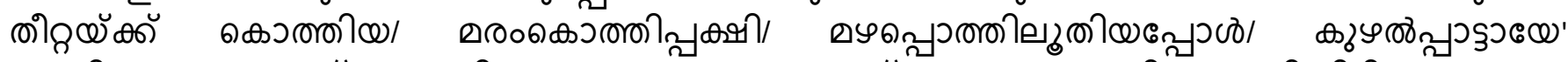

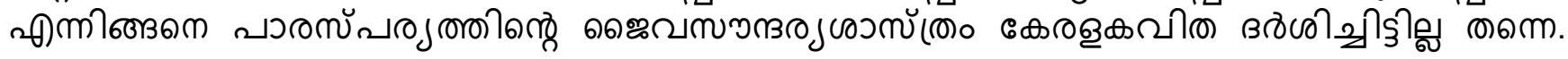

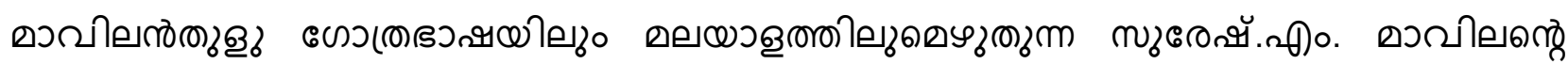

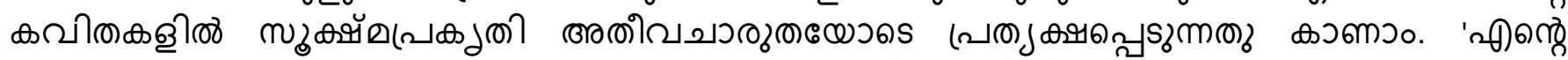

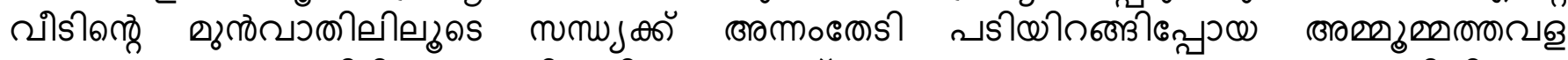

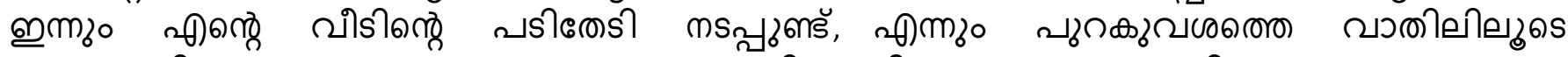

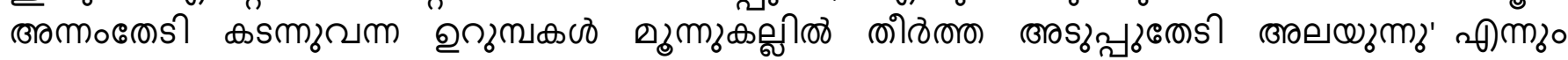




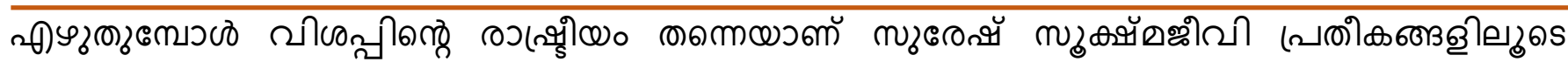

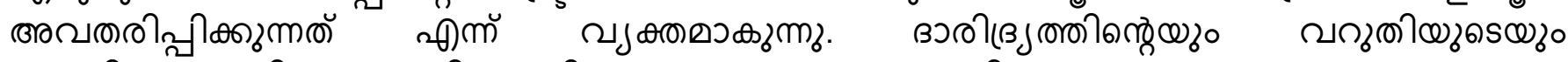

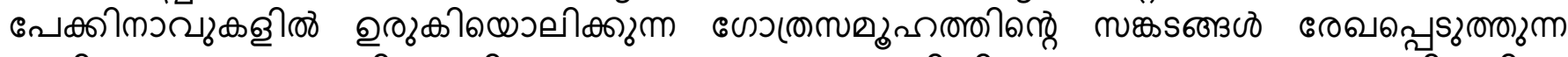

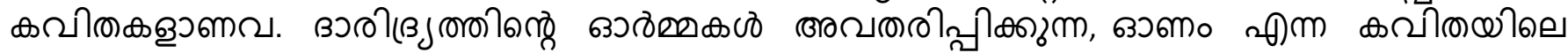

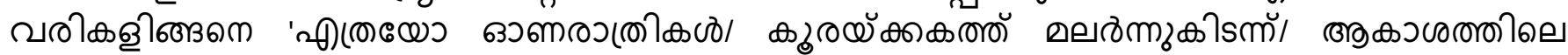

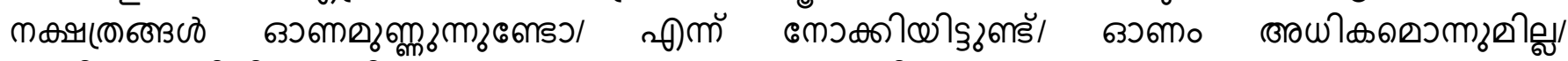

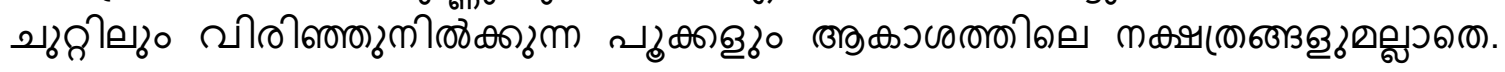

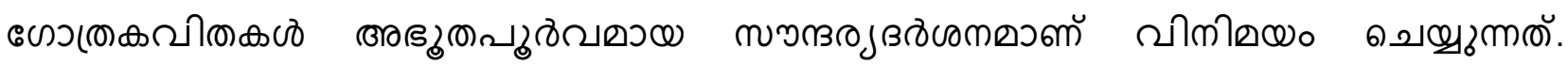

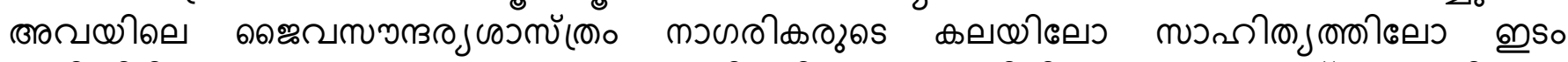

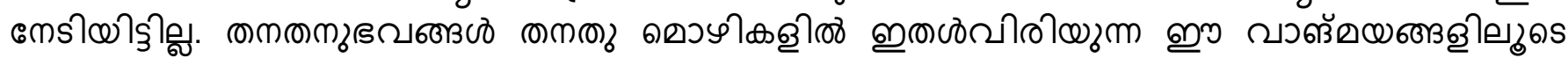

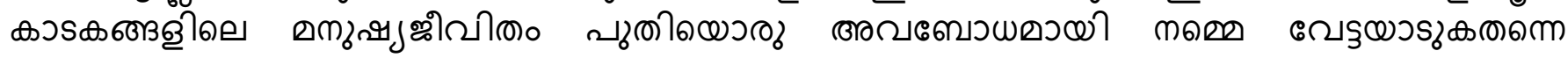
๑ एप्रु०.

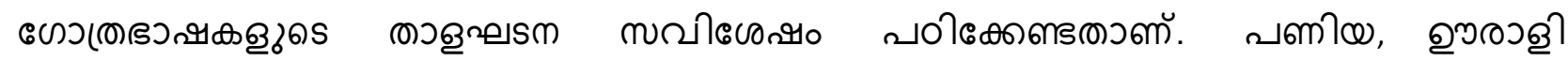

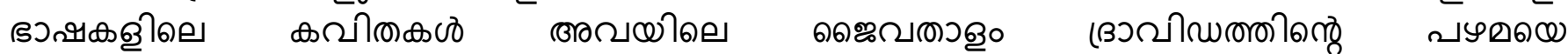

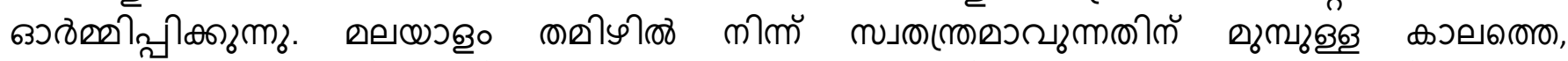

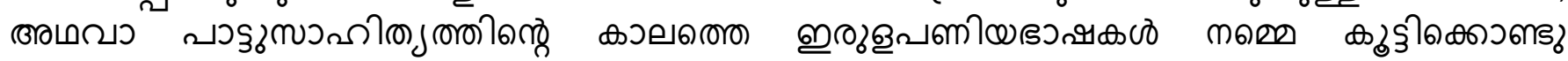

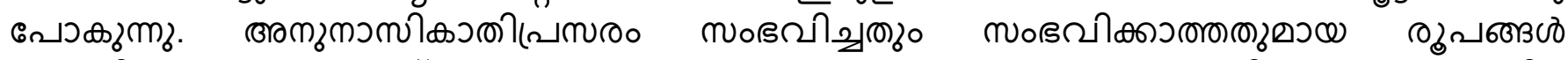

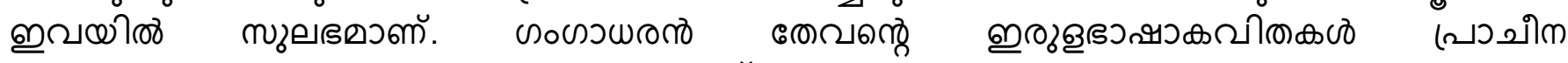

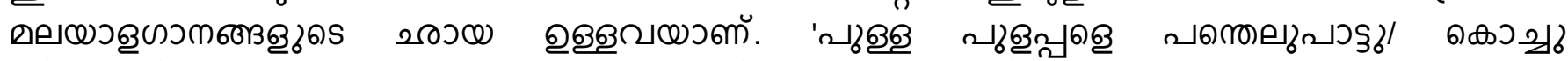

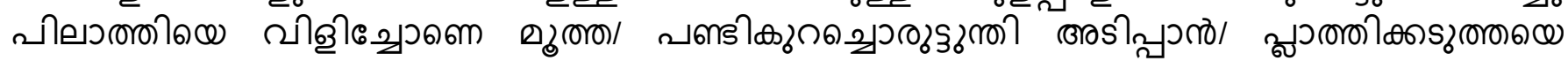

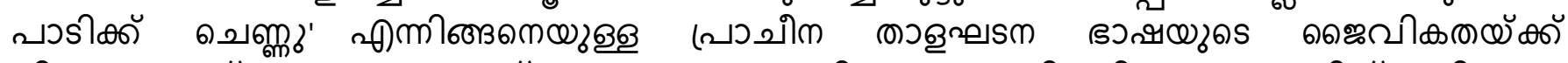

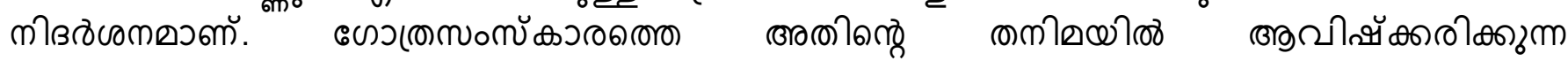

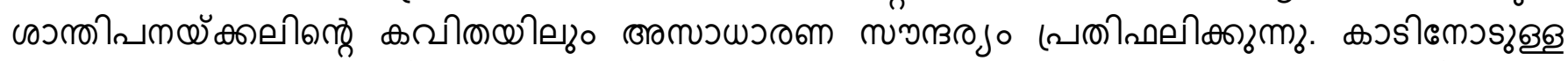

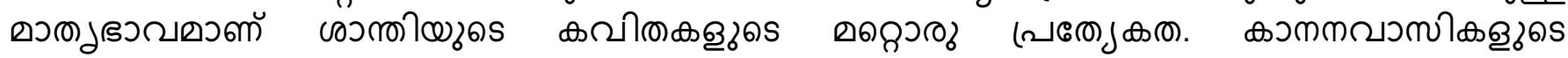

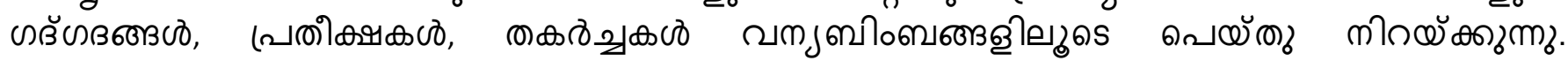

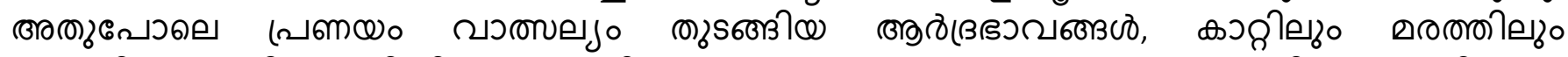

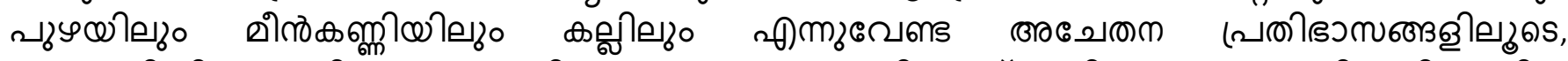

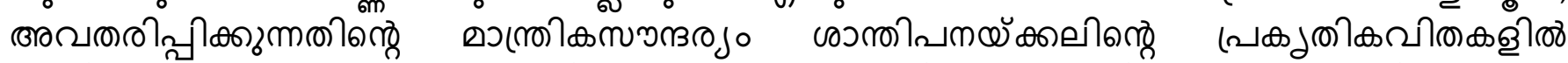

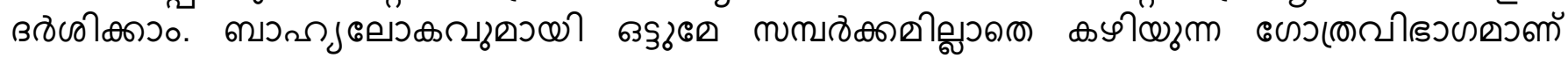

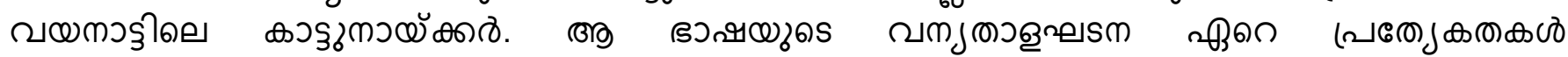

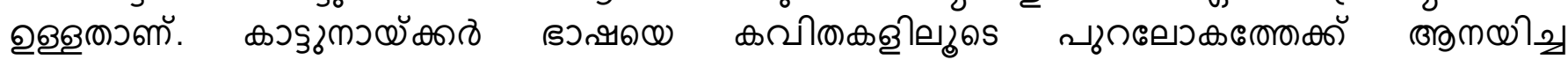

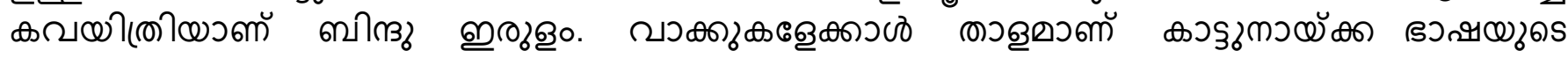

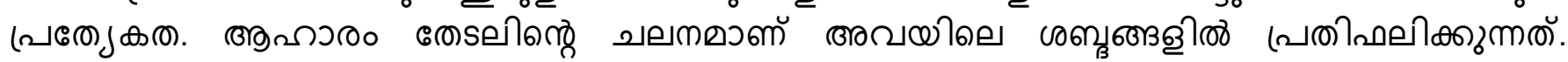

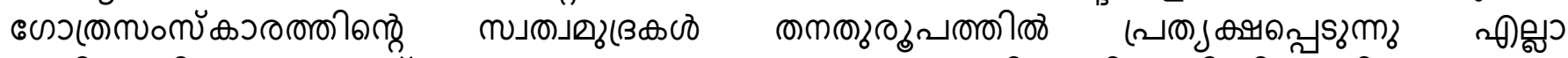

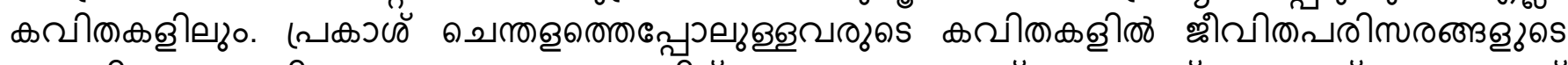

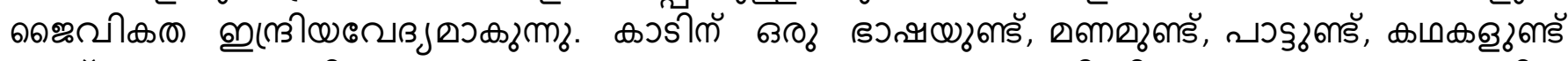

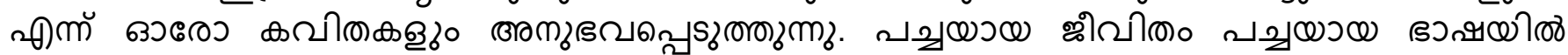

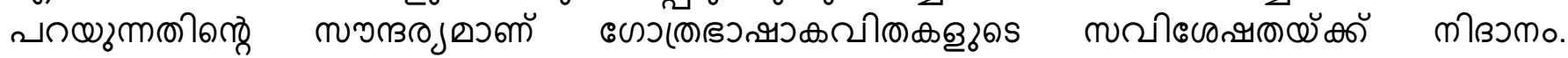

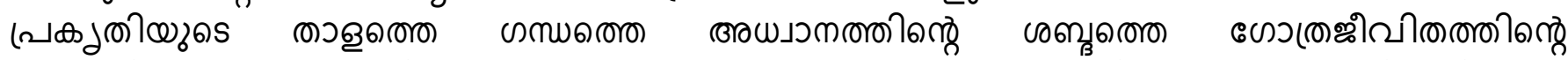

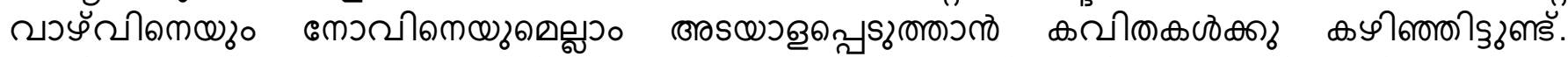

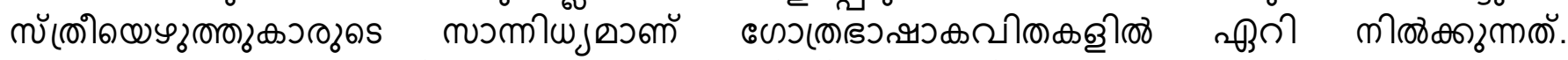

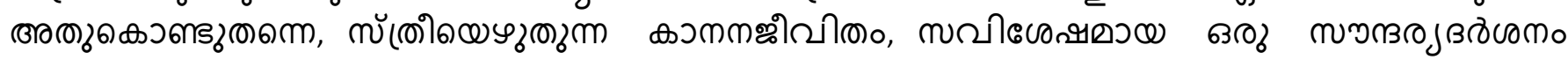

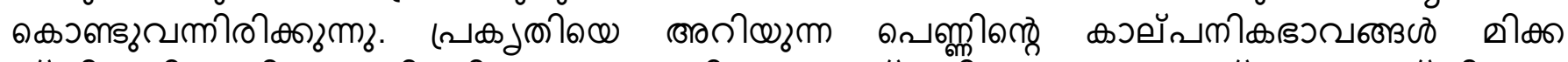

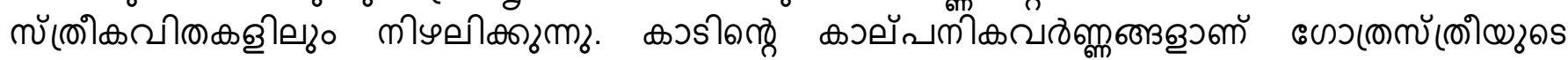

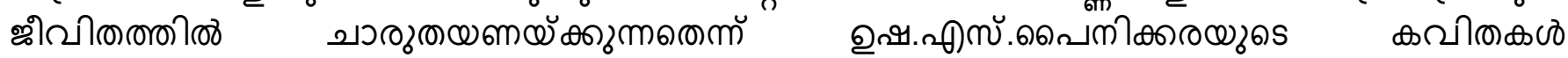

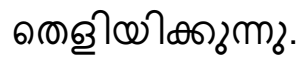




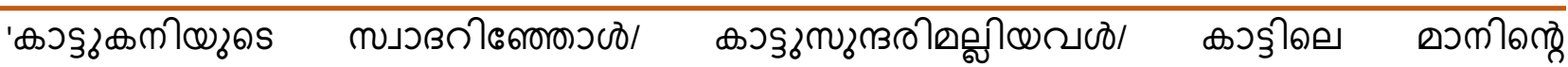

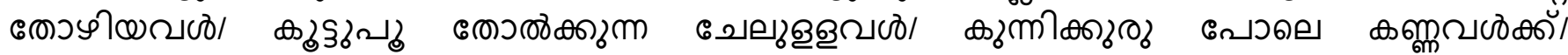

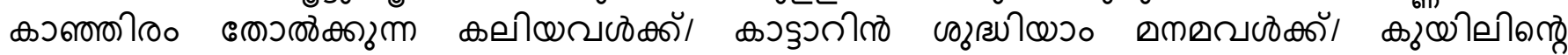

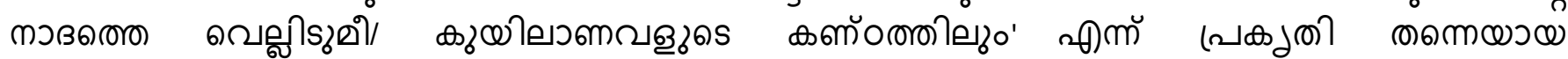

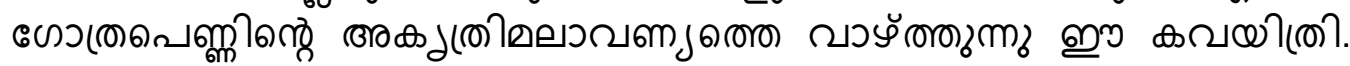

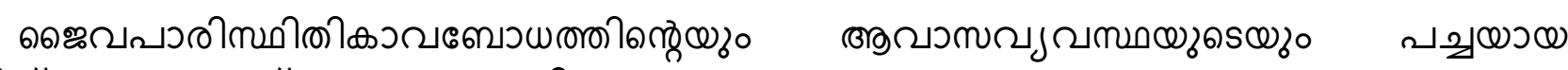

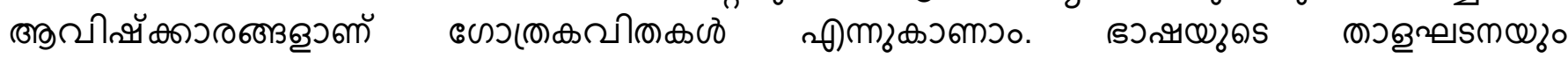

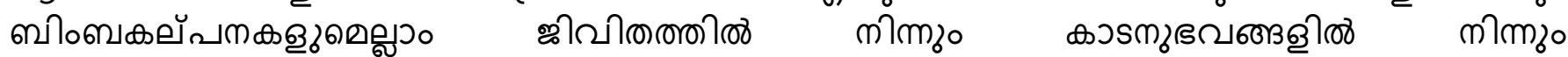

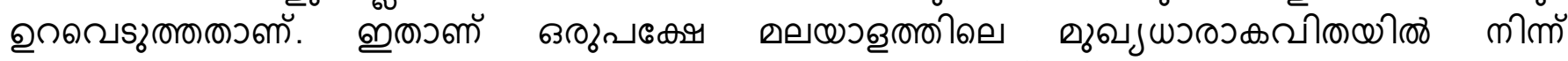

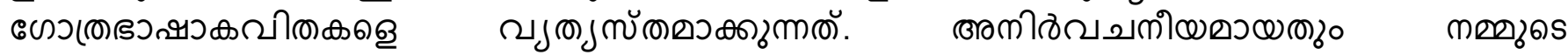

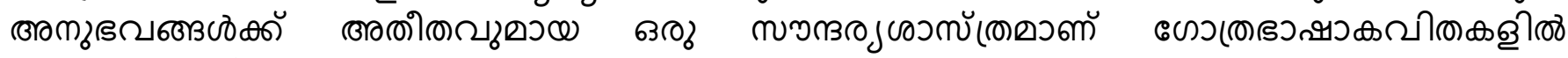

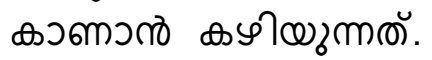

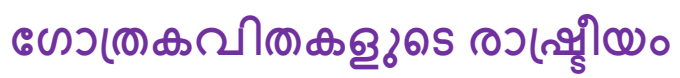

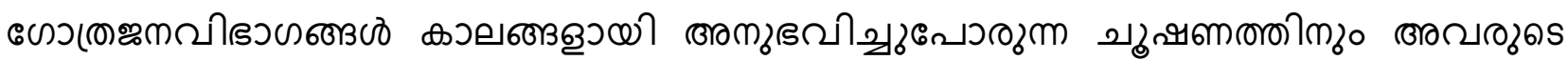

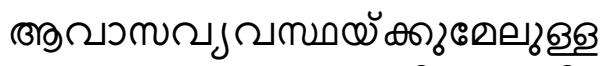
๘ய

(ी)

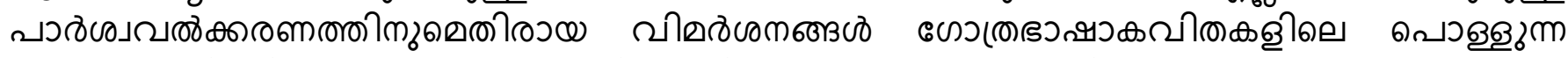

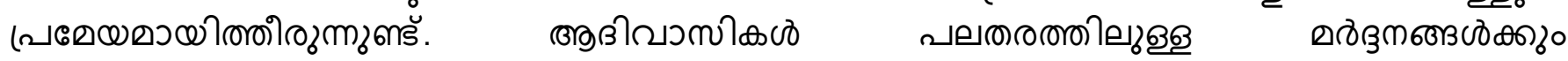

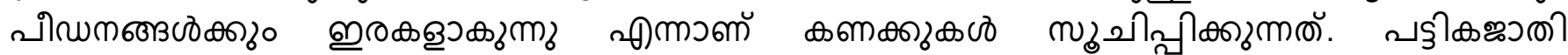

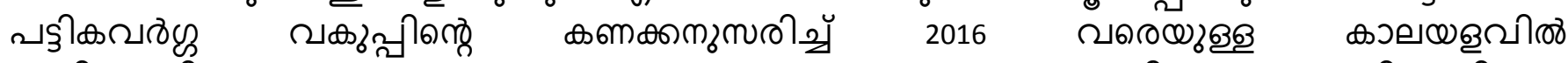

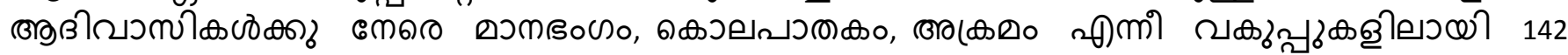

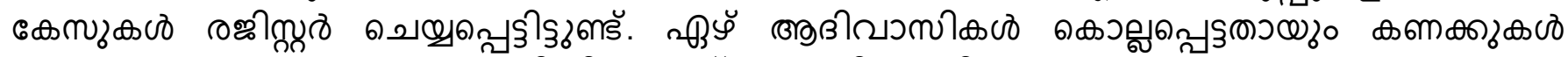

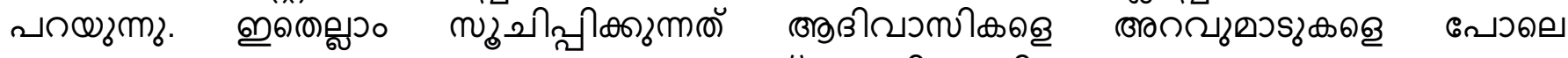

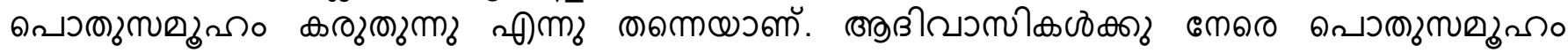

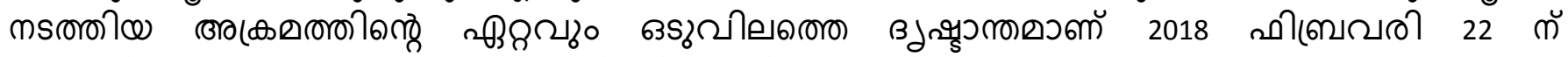

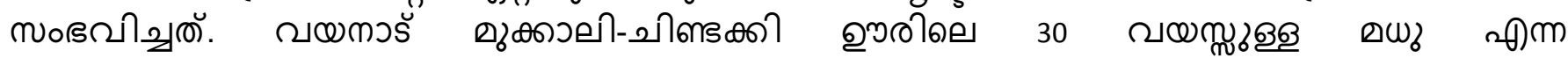

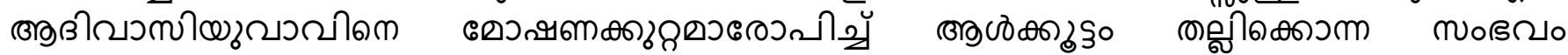

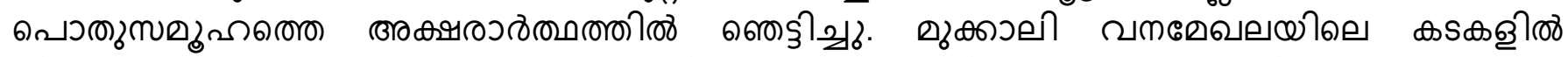

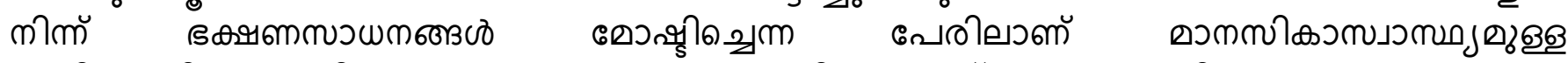

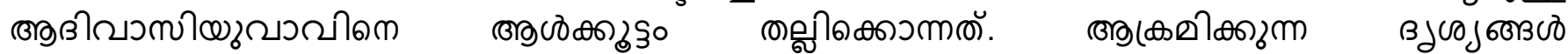

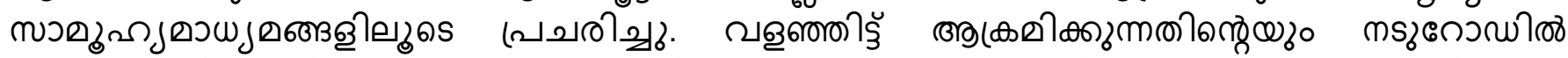

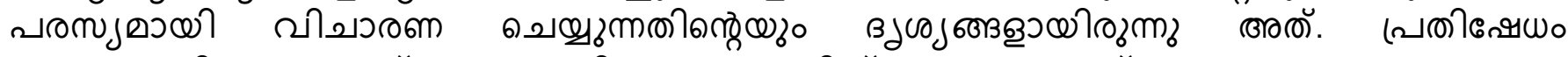

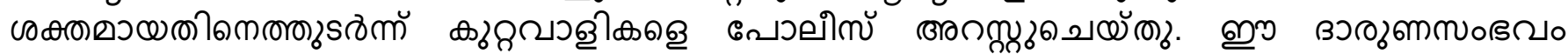

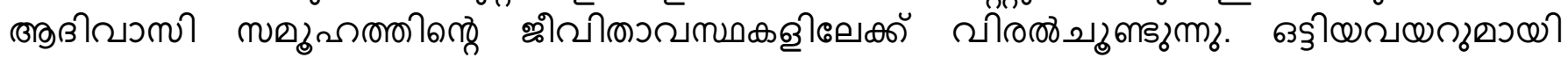

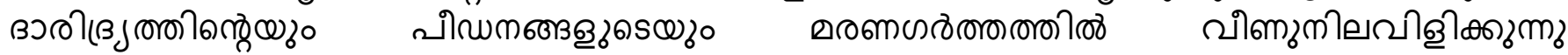

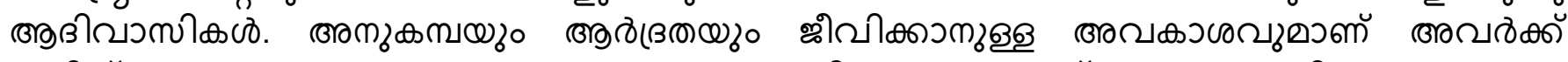

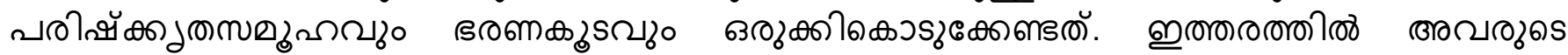

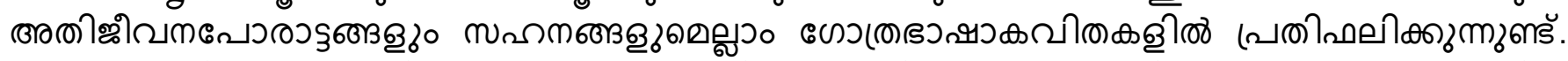

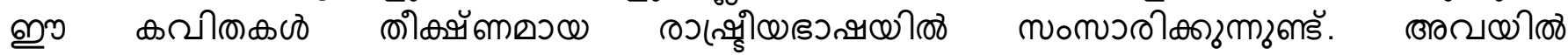

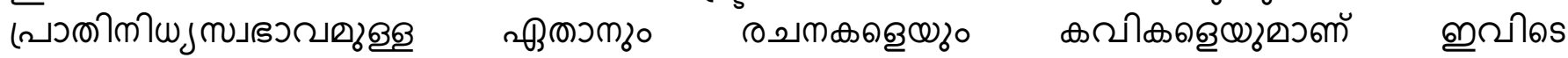

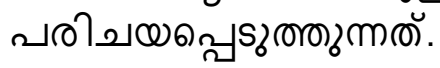

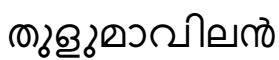

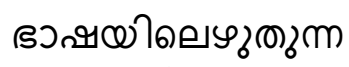

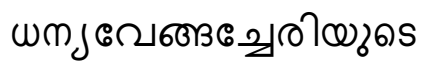

கூவிகையठ

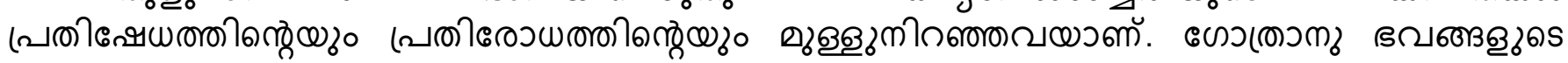

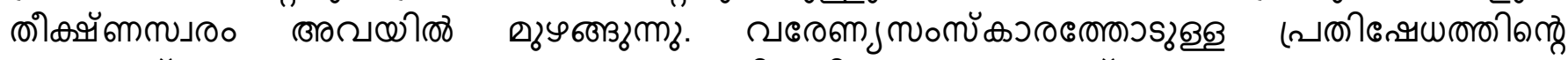

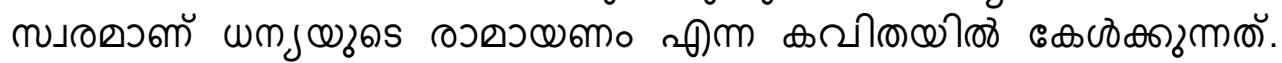




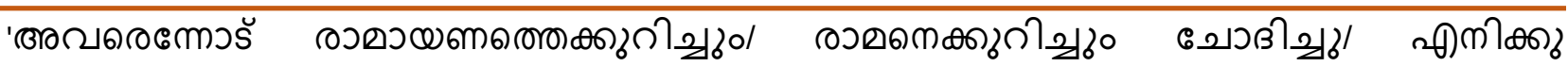

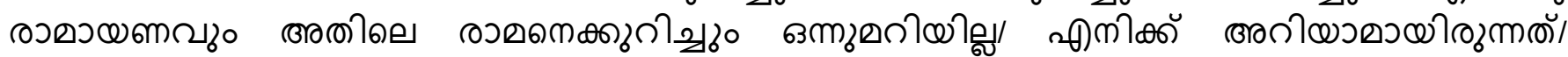

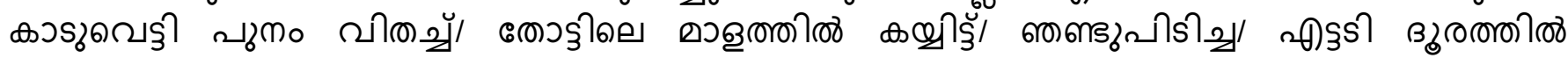

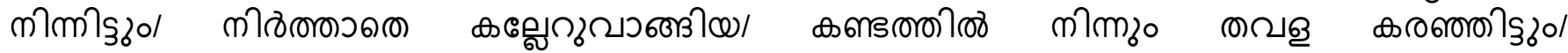

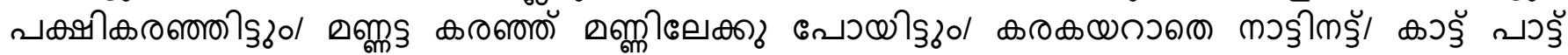

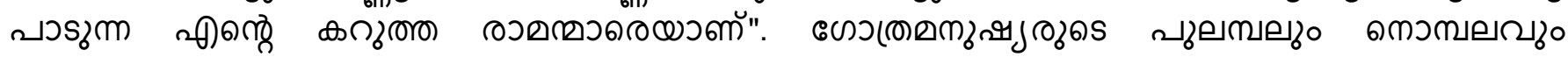

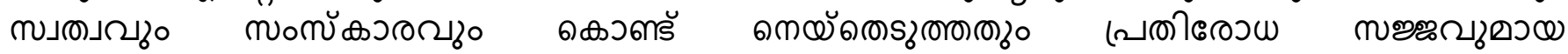

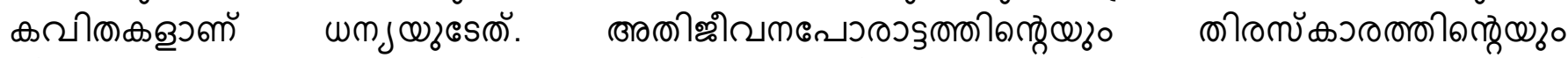

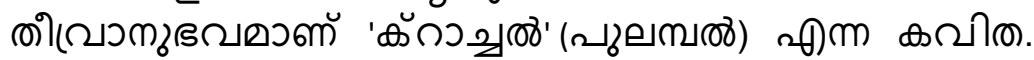

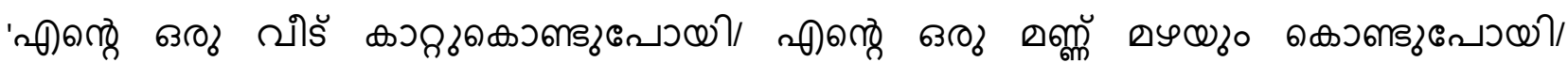

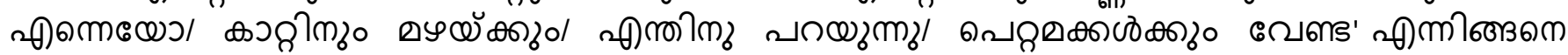

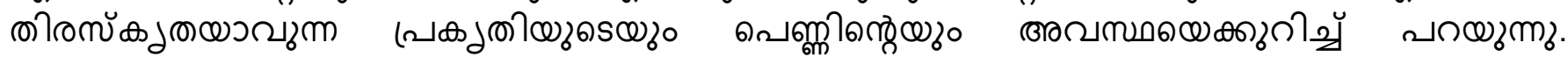

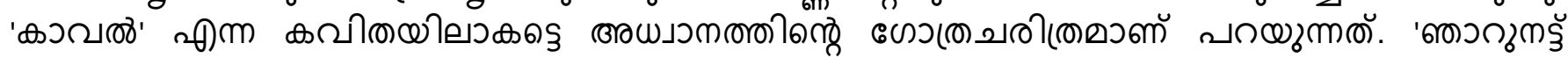

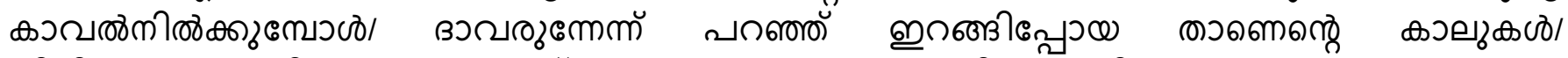

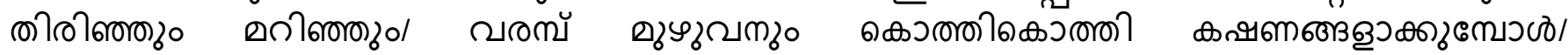

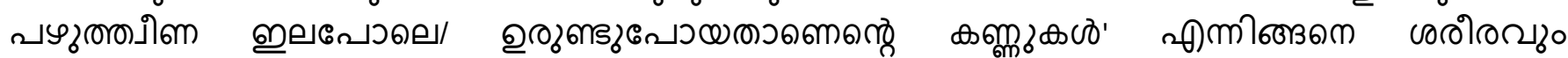

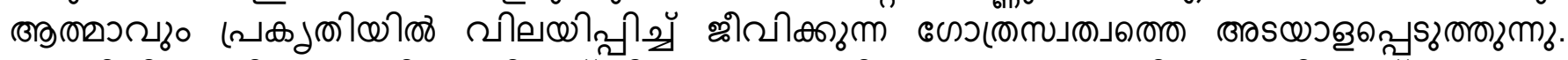

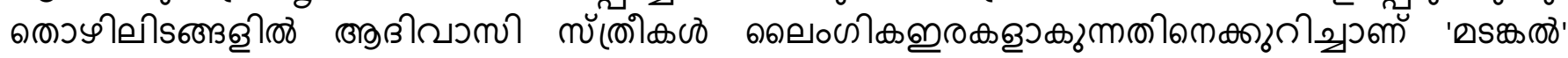

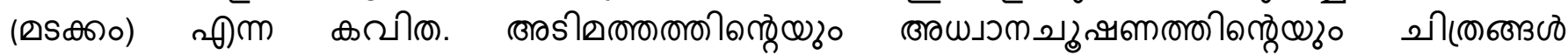

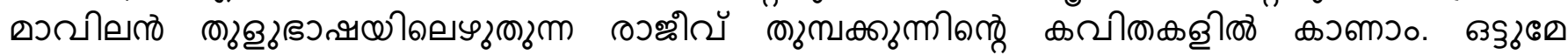

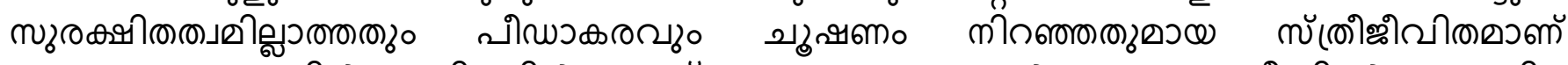

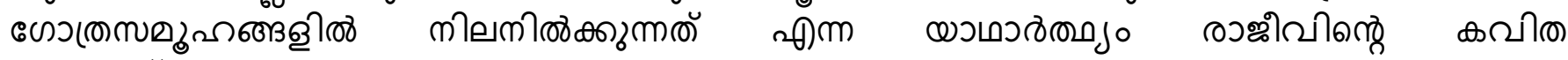

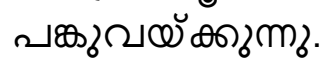

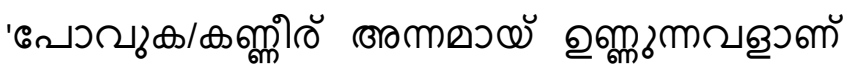

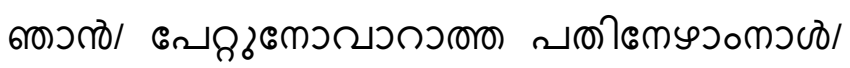

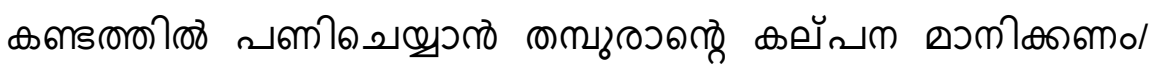

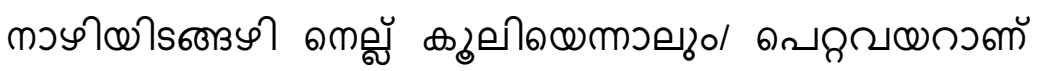

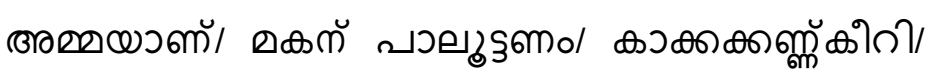

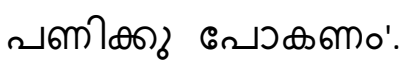

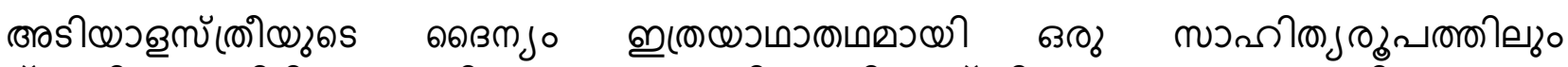

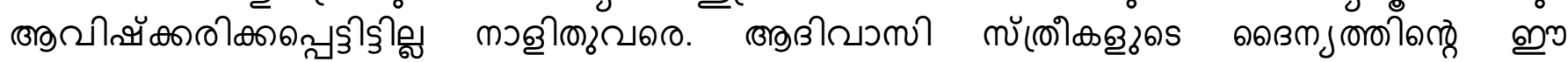

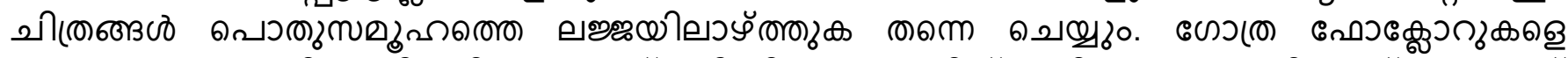

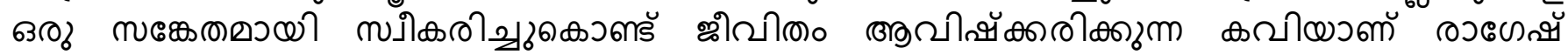

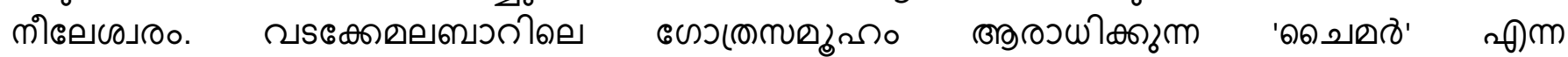
வ

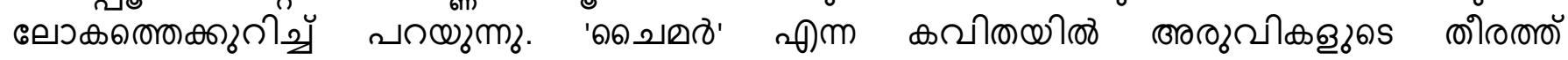

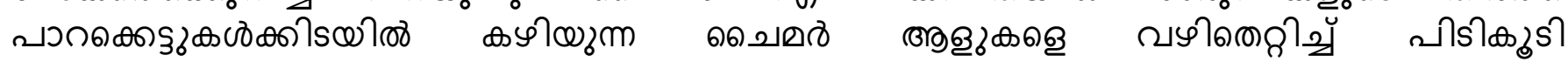

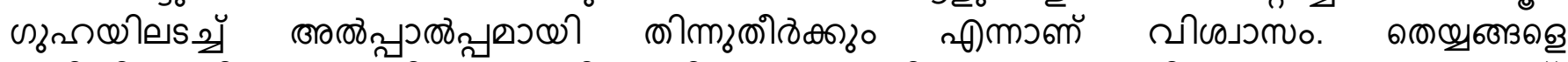

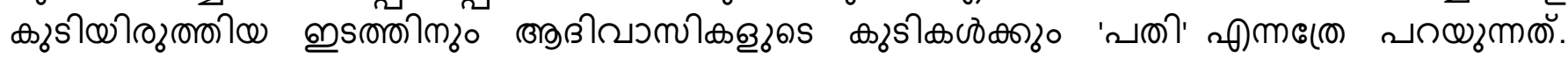

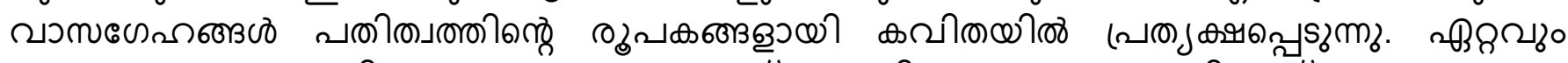

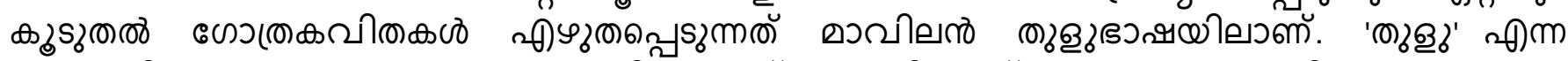

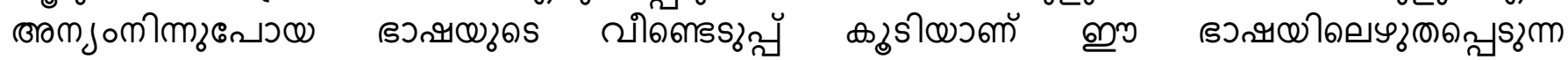

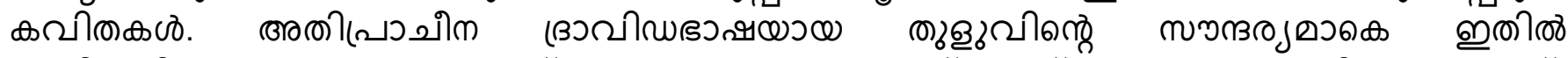

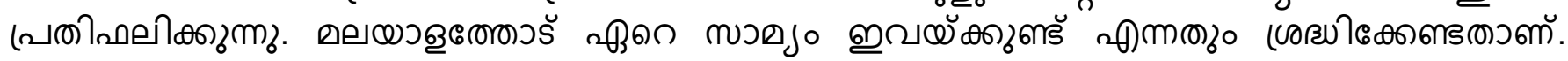




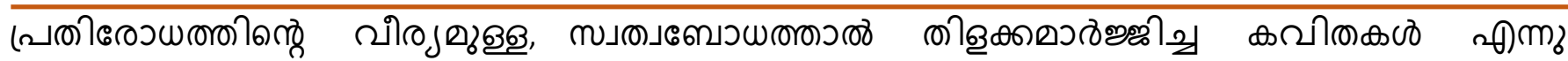

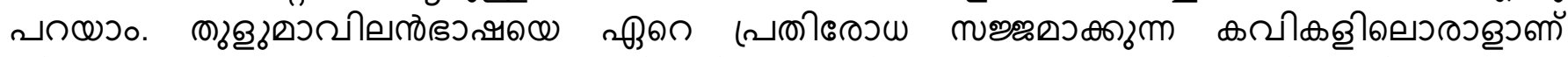

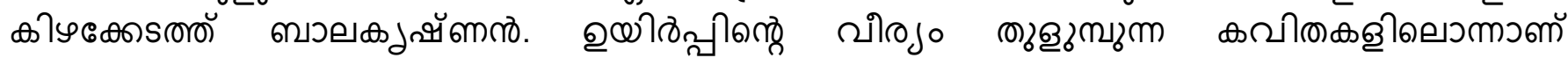

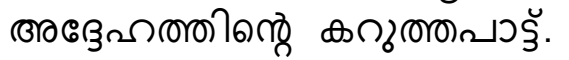

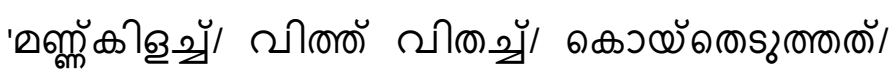

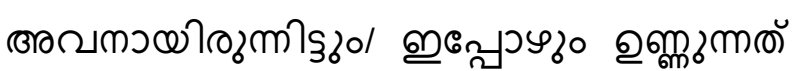

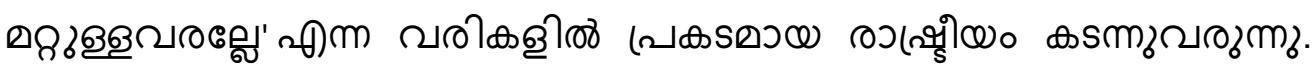

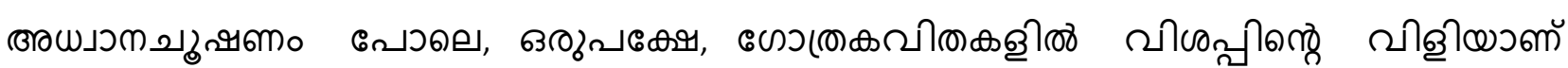

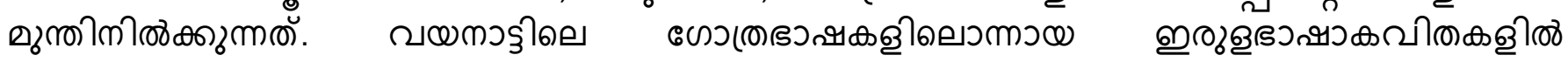

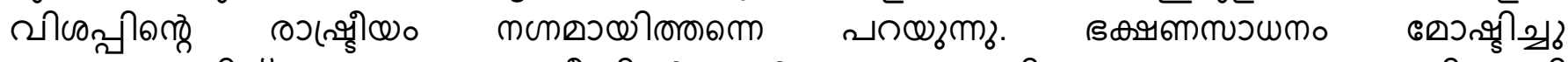

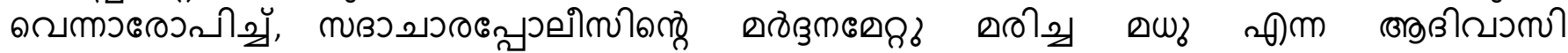

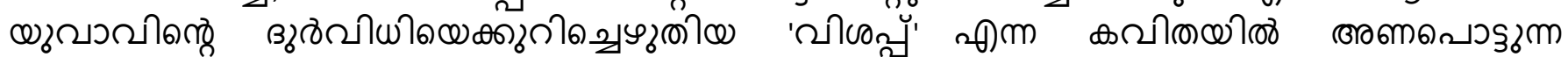

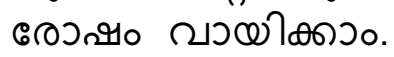

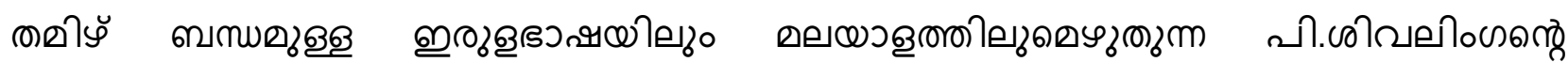

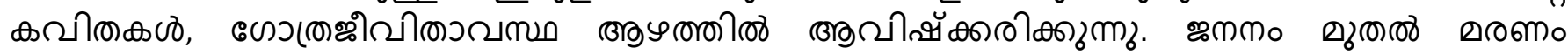

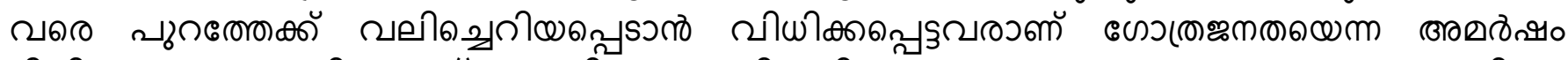

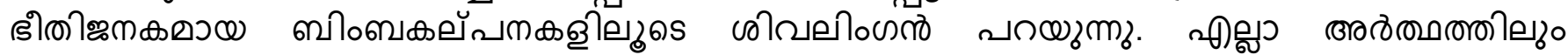

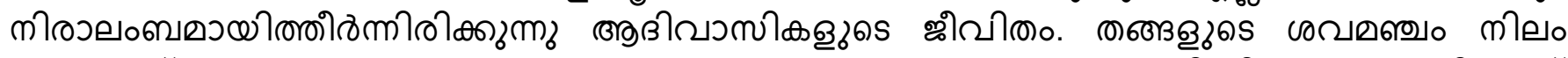

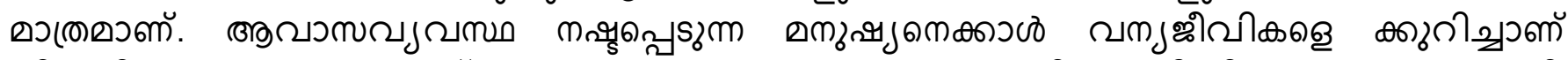

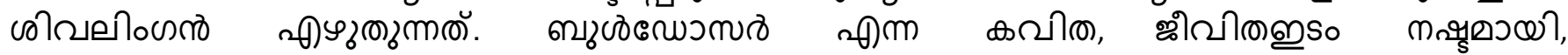

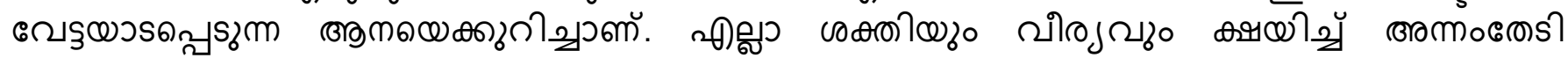

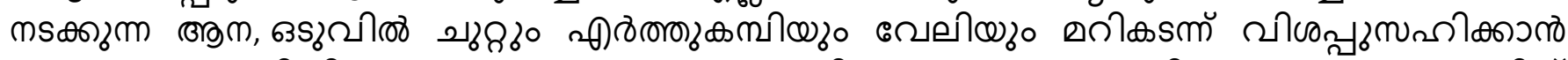

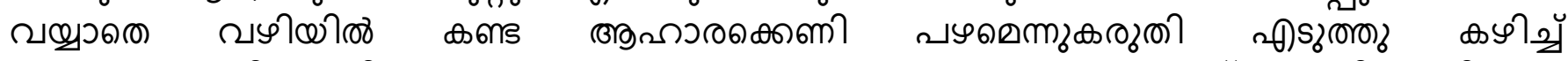

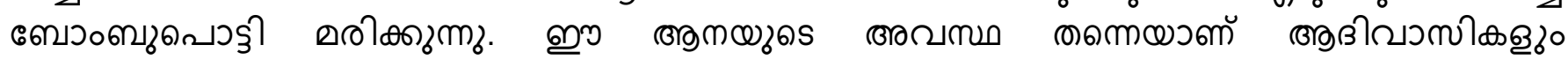

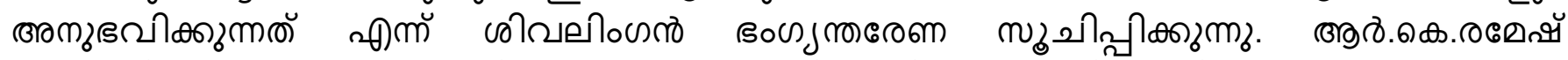

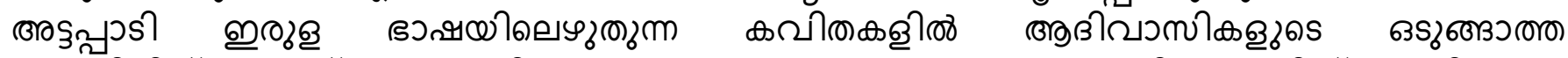

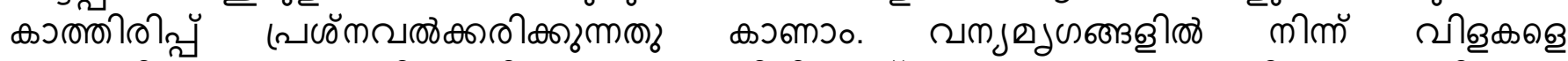

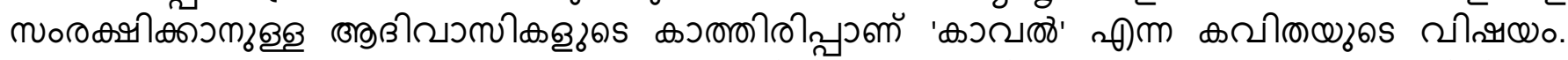

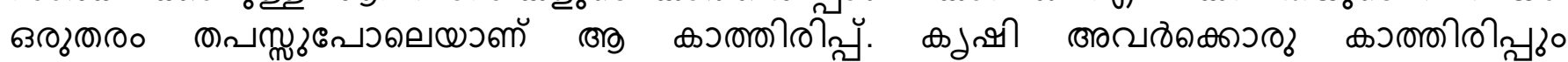

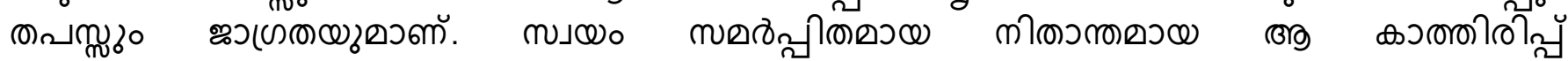

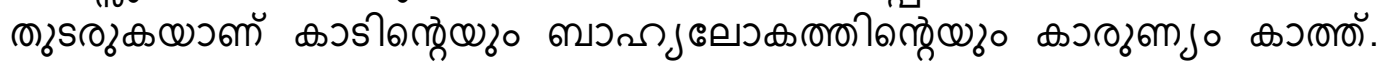

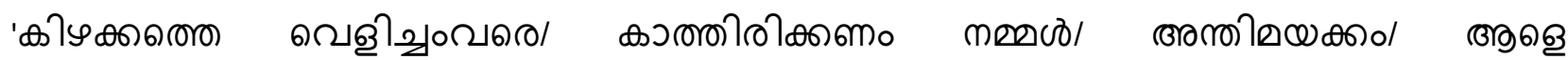

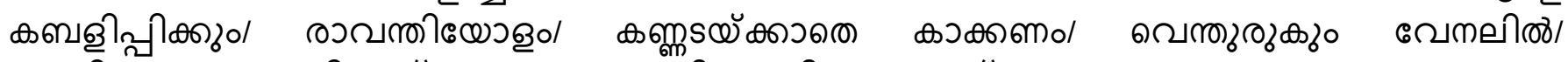

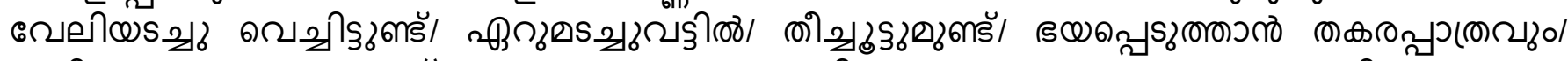

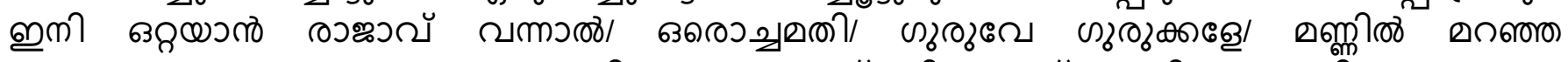

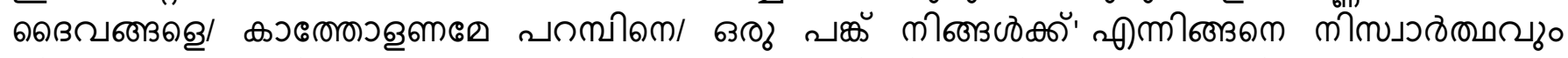

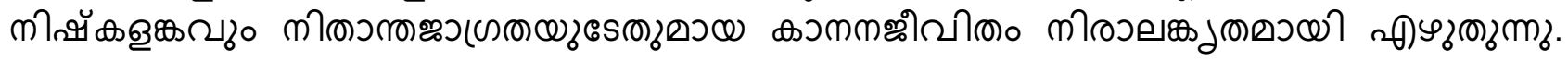

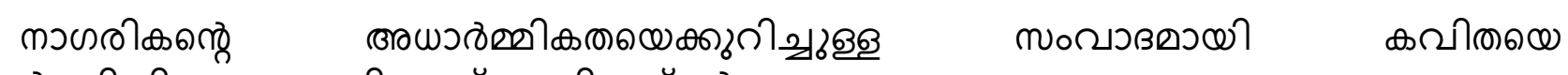

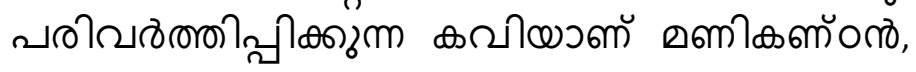

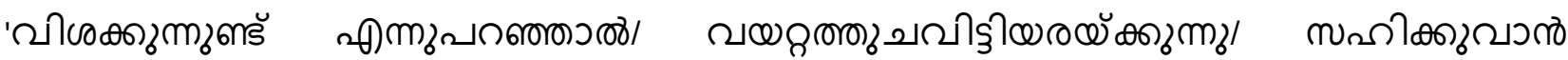

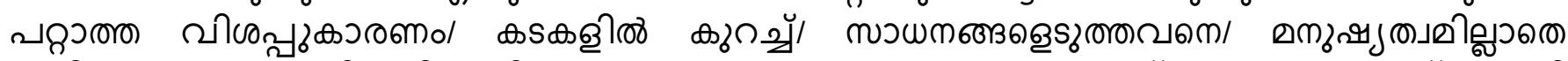

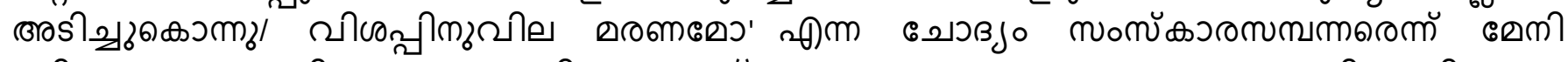

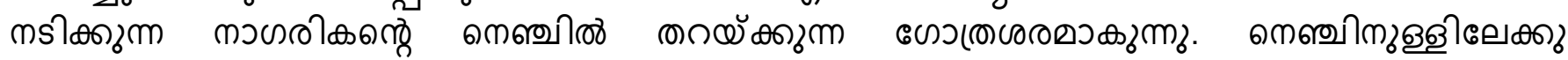

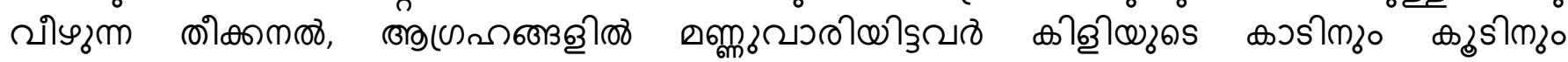




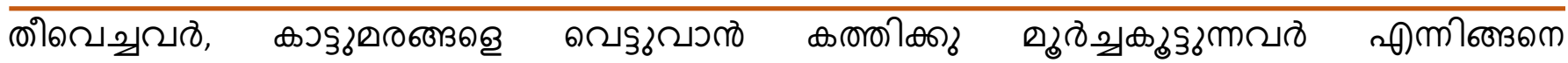

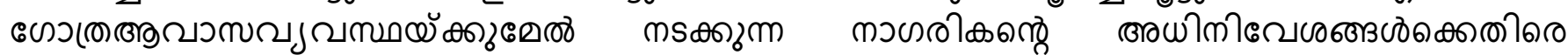

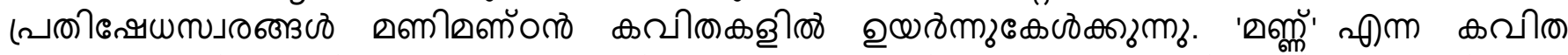

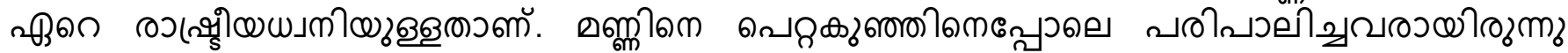

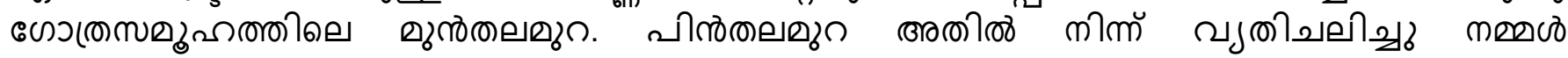

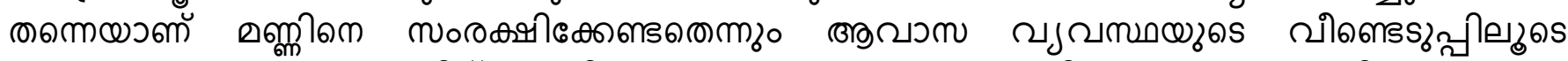

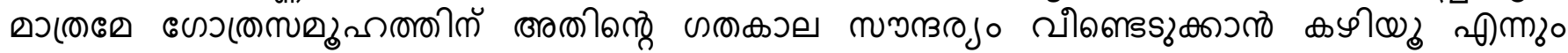

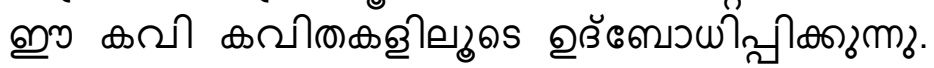

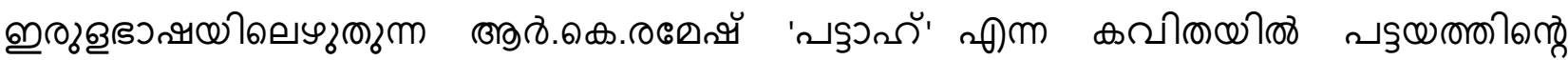

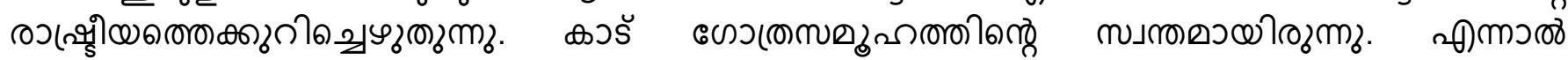

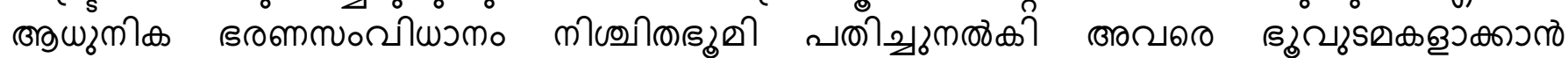

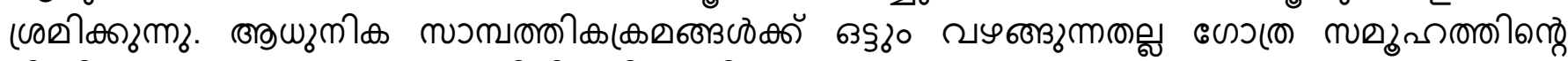

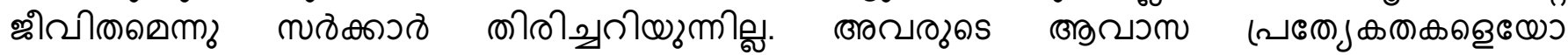

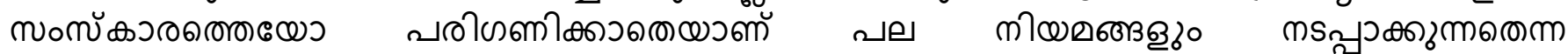

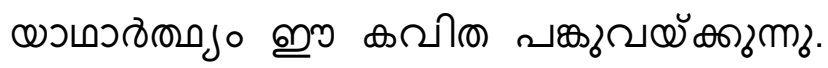

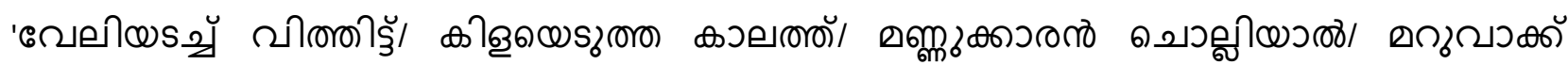

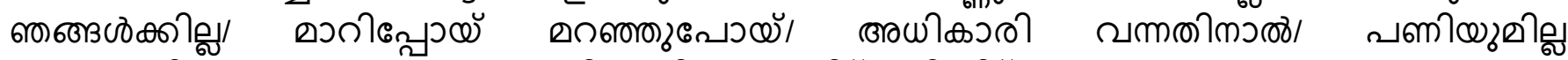

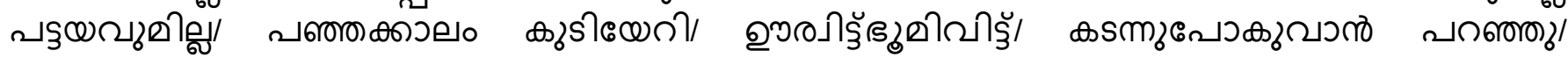

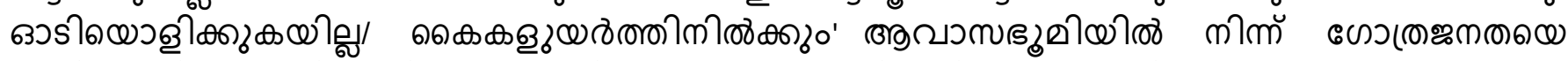

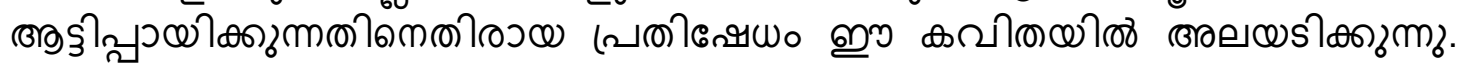

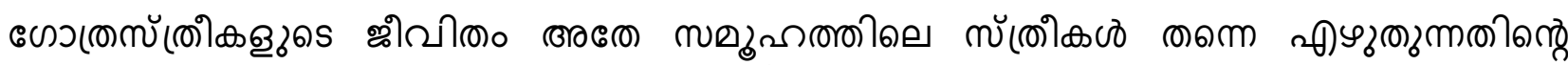

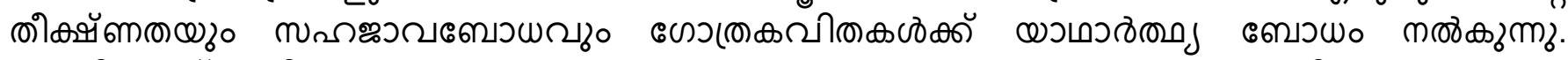

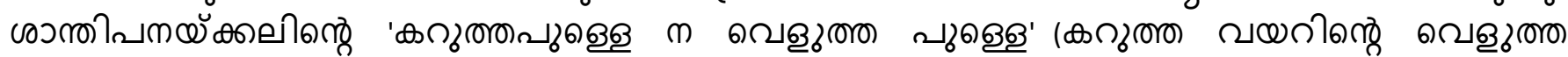

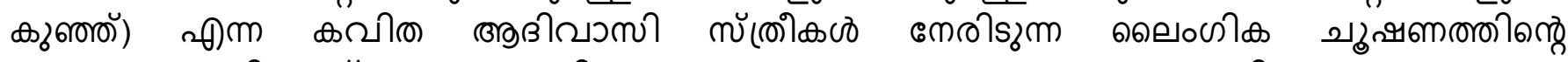

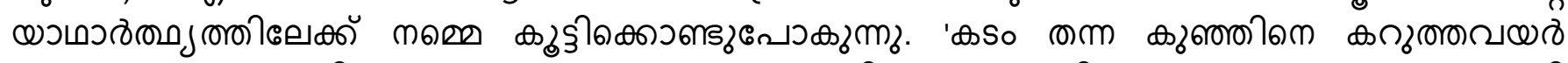

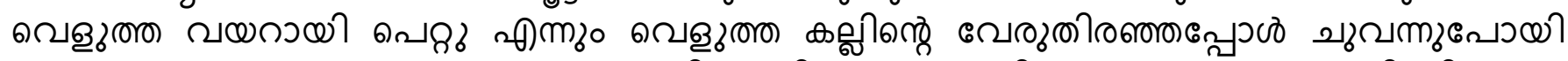

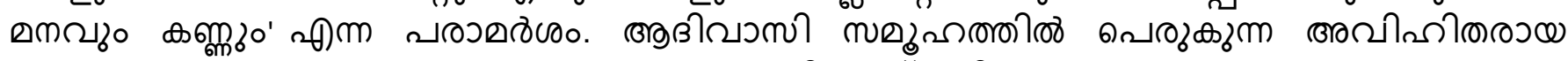

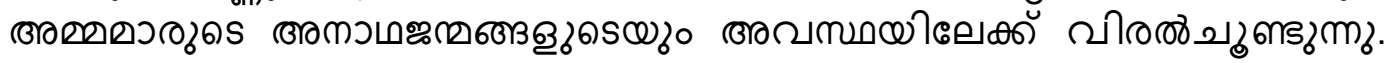

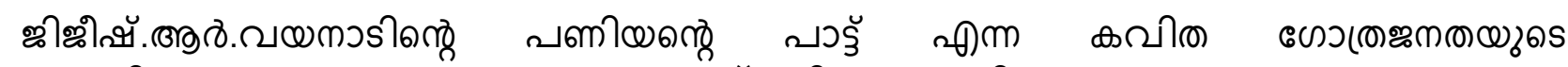

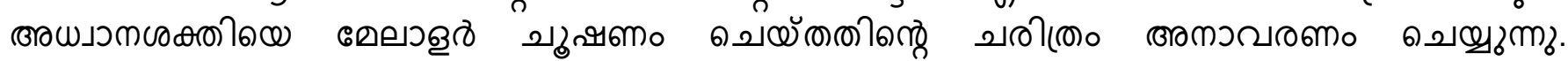

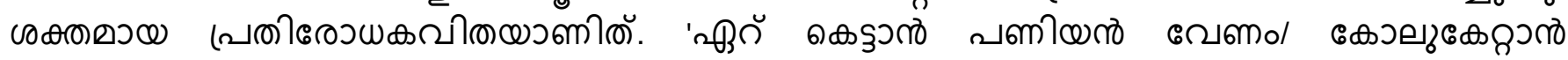

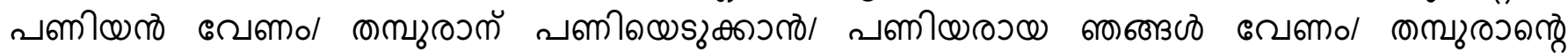

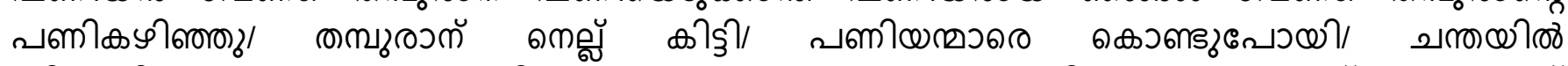

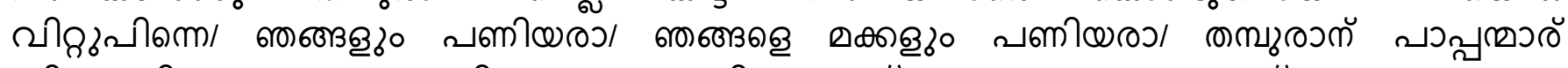

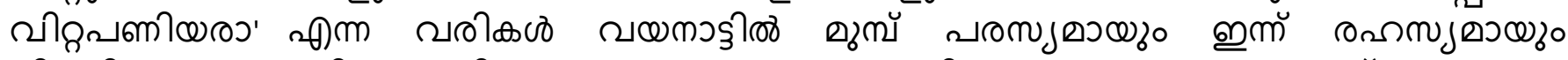

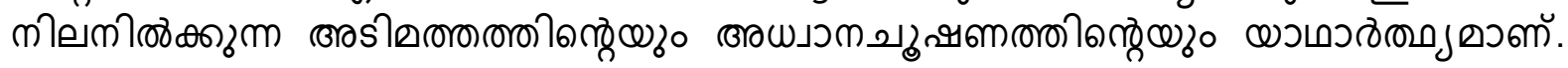

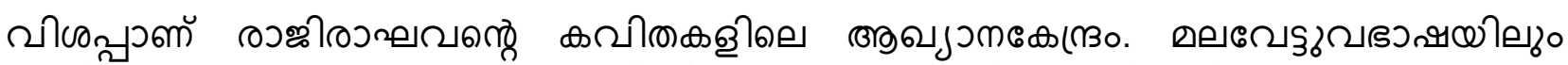

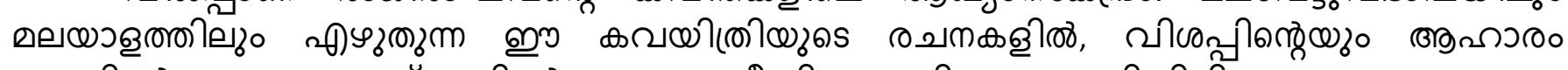

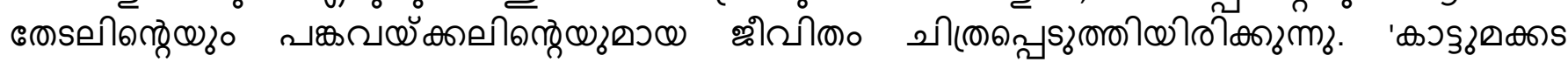

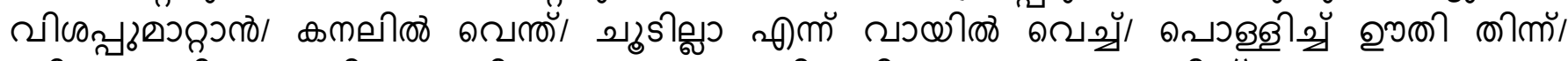

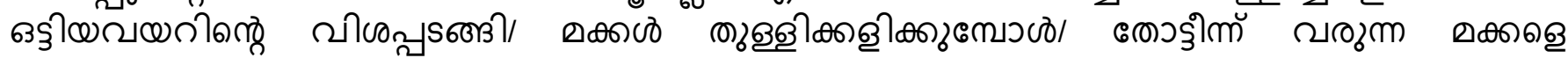

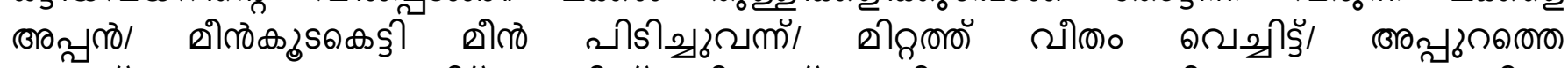

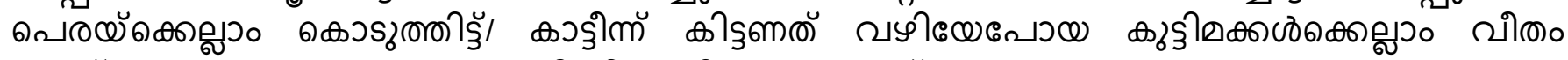

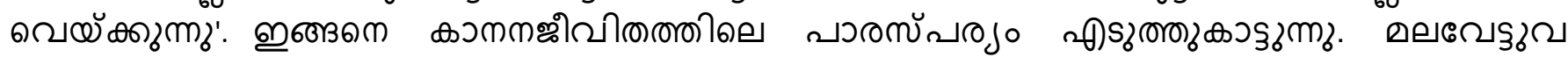

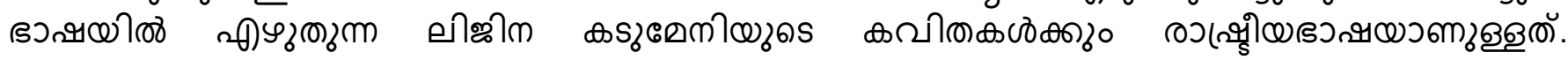




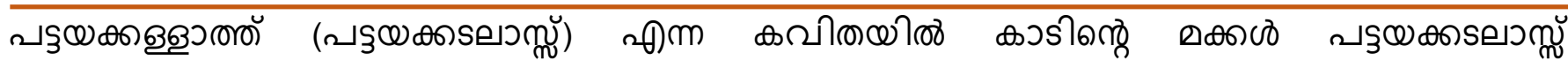

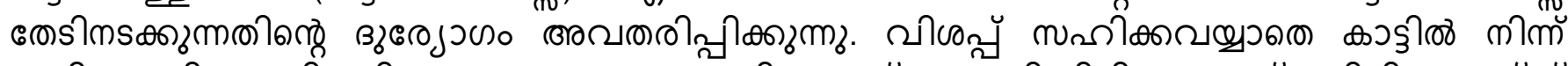

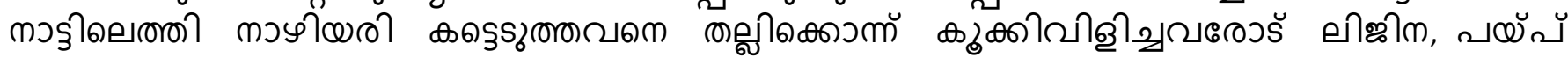

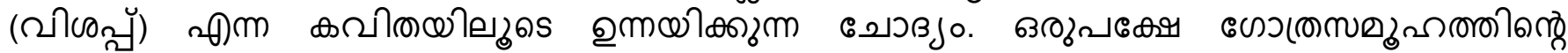

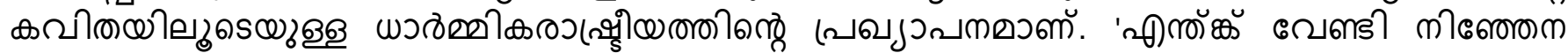

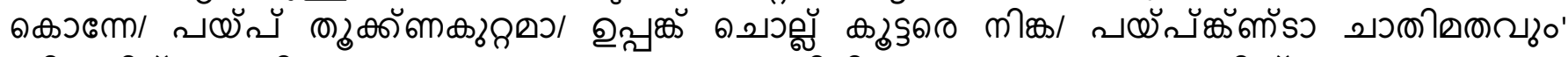

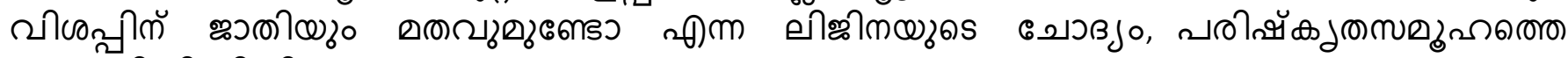
ஹா

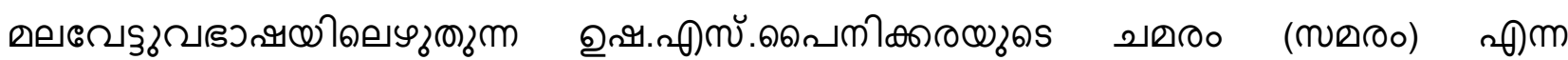

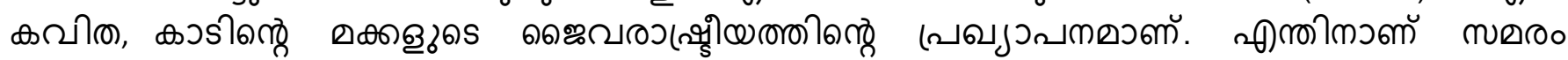

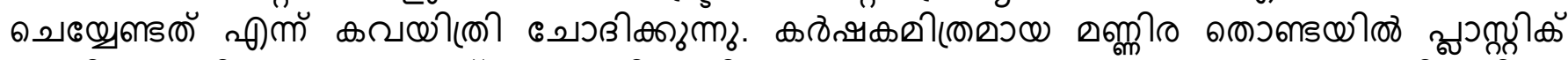

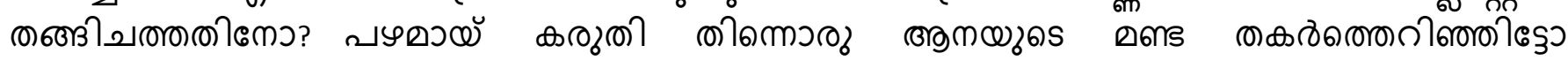

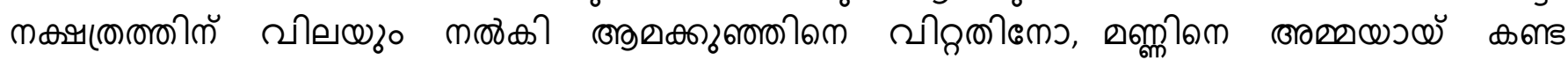

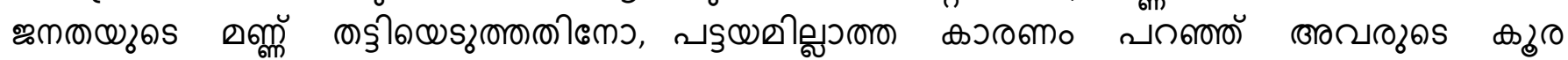

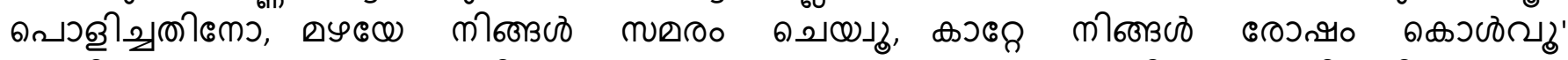

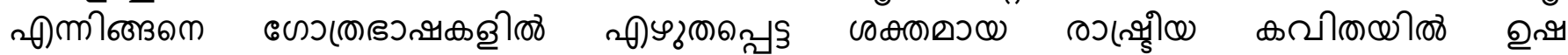

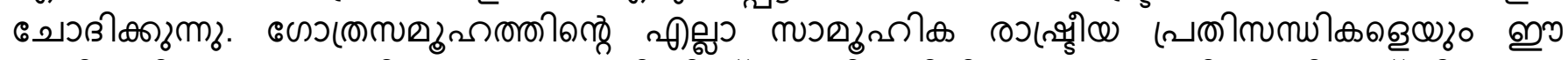

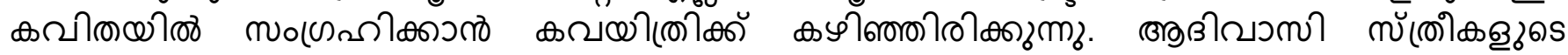

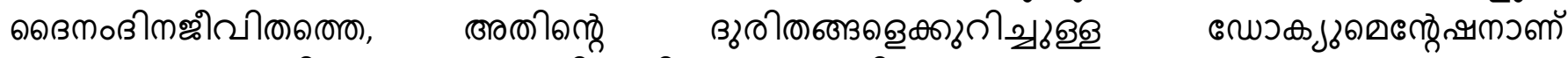

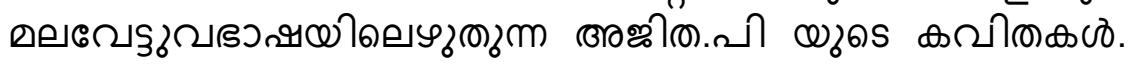

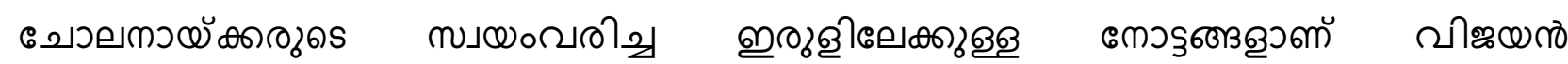

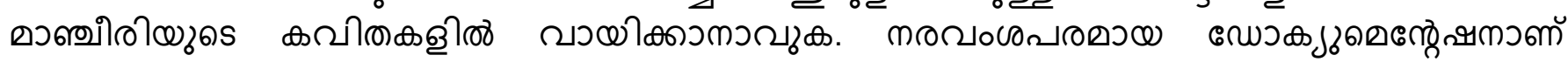

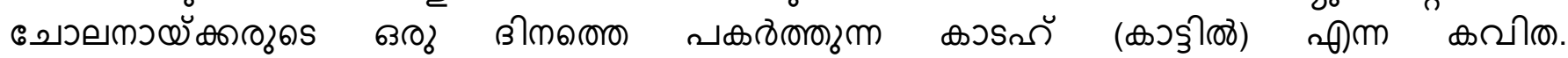

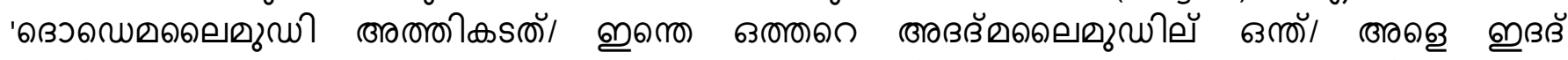

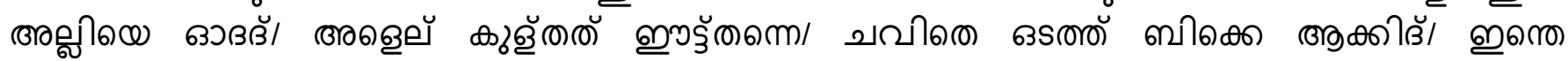

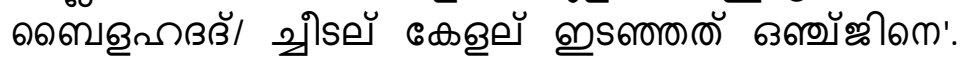

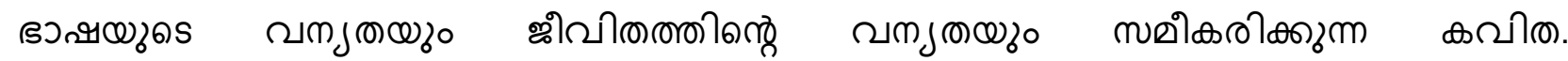

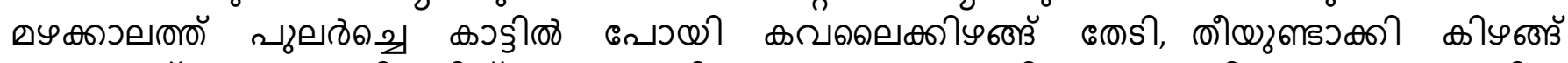

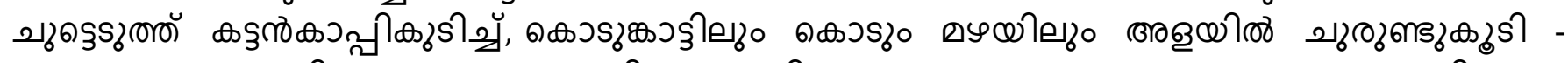

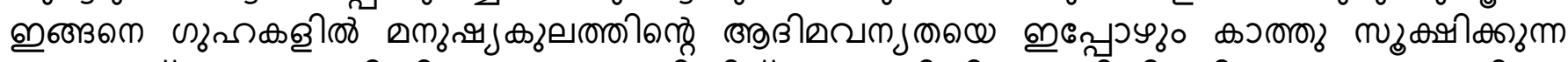

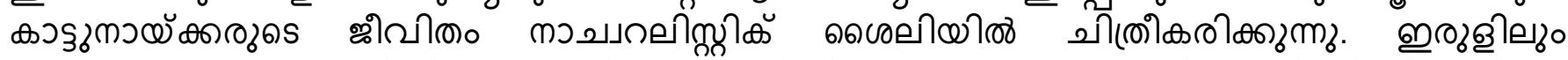

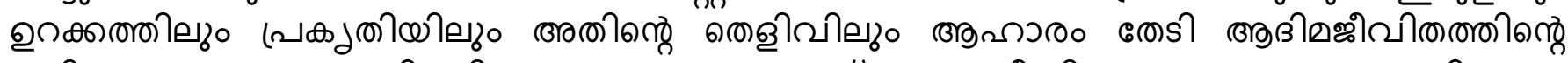

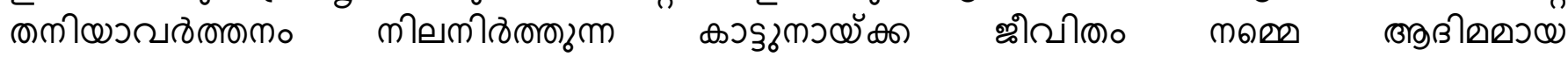

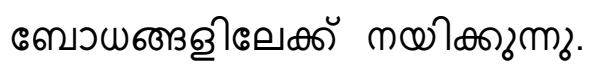

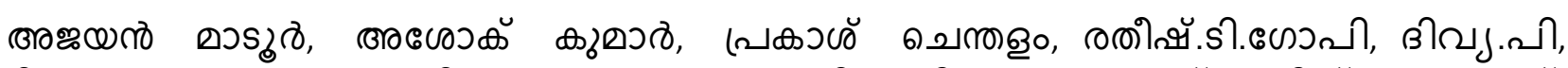

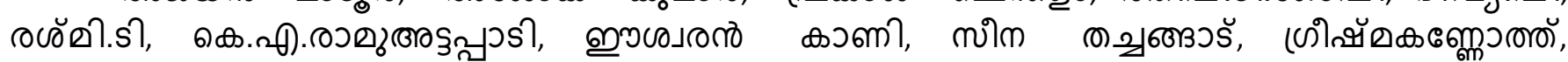

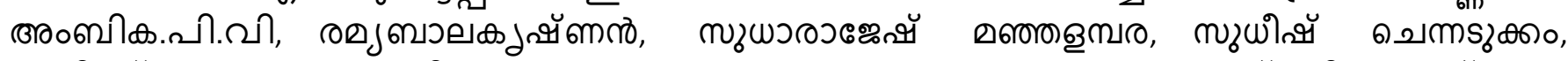

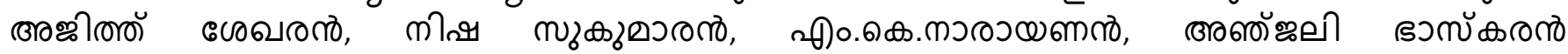

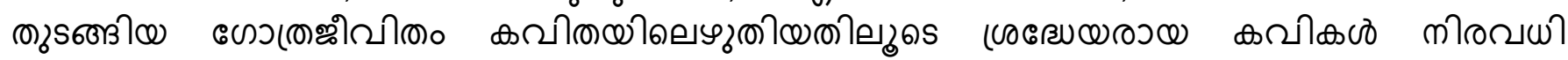

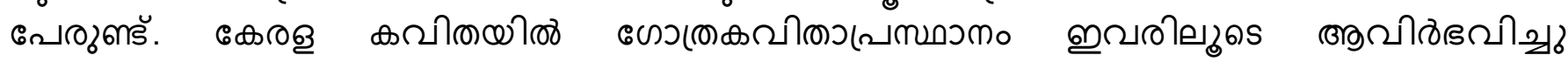

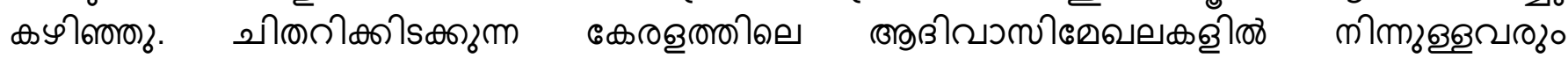

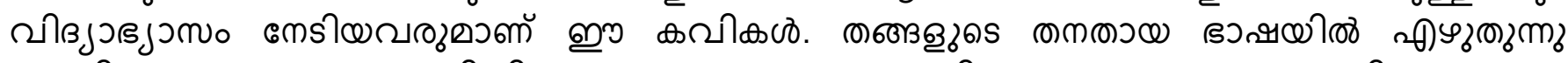

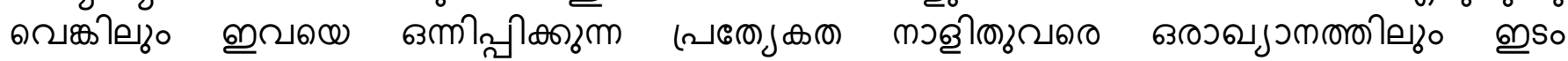

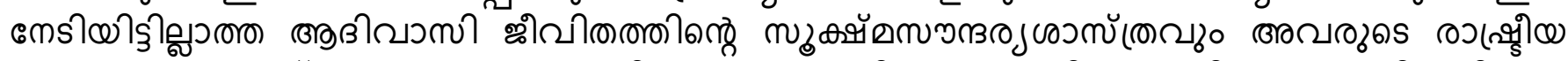

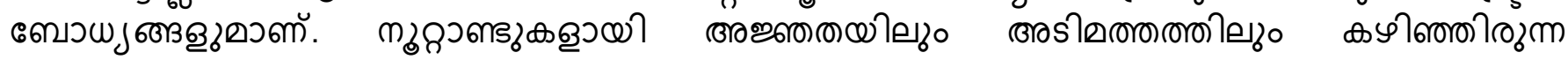




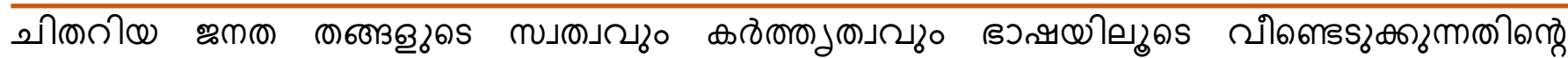

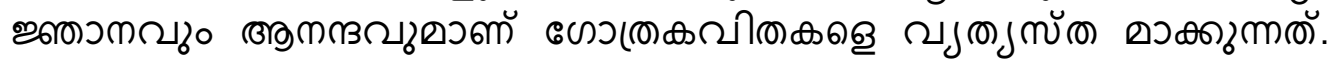

\section{Conclusion}

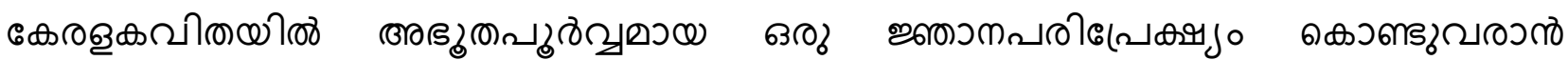

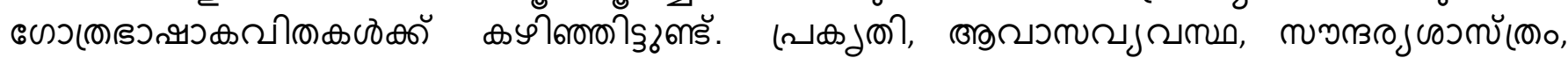

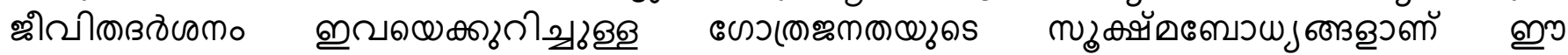

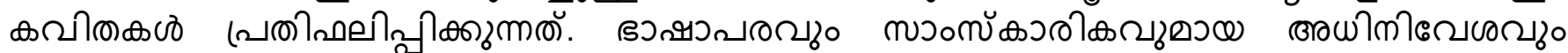

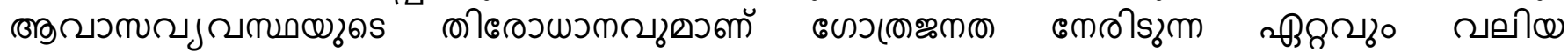

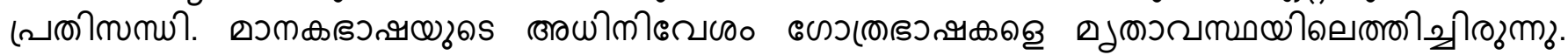

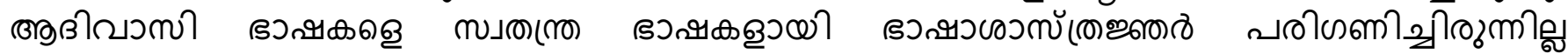

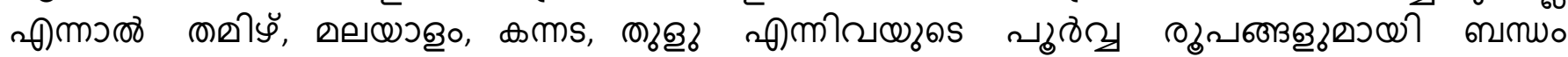

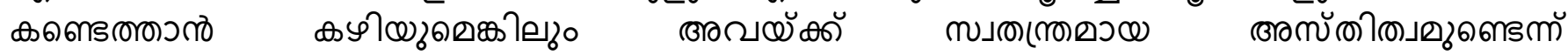

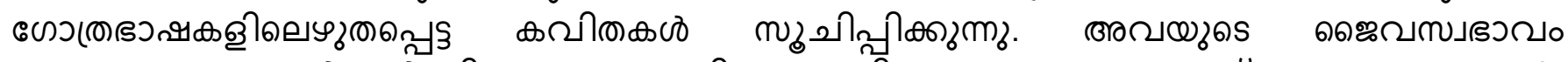

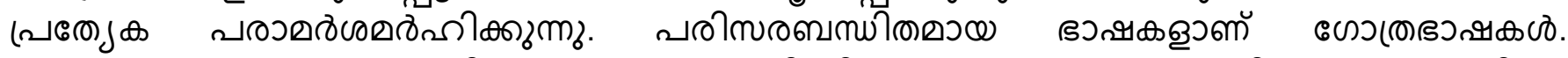

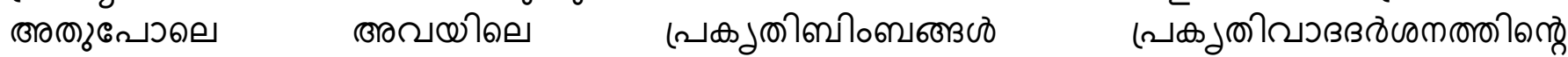

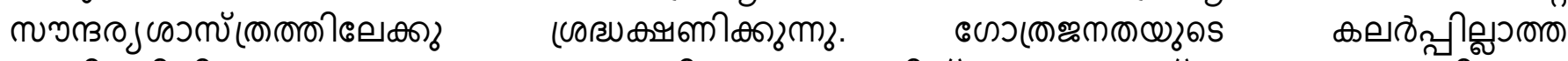

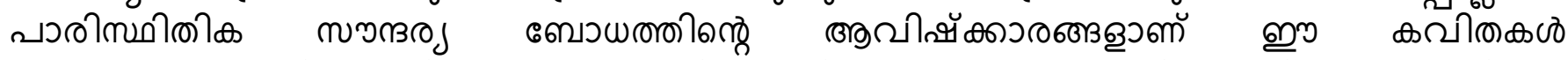

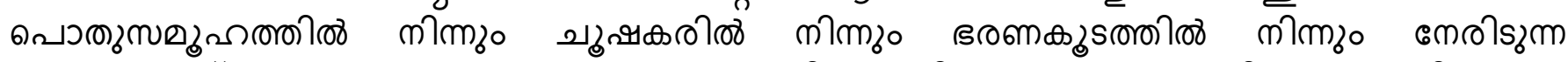

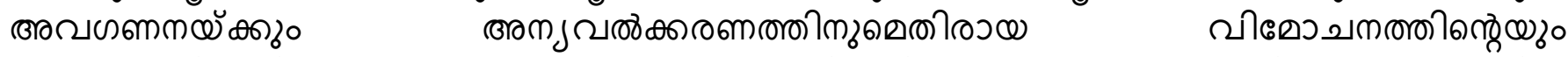

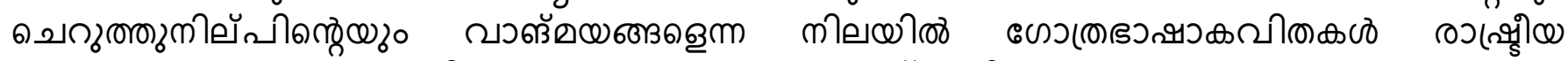

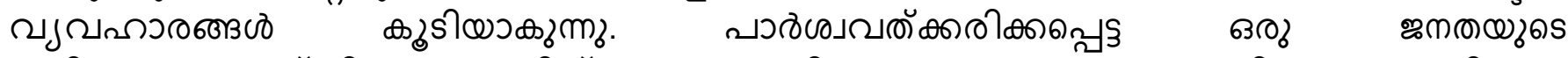

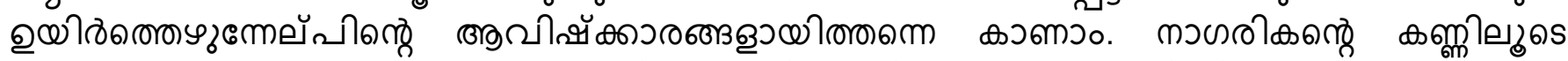

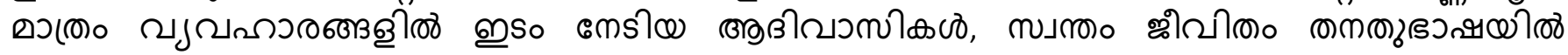

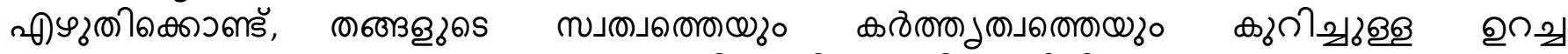

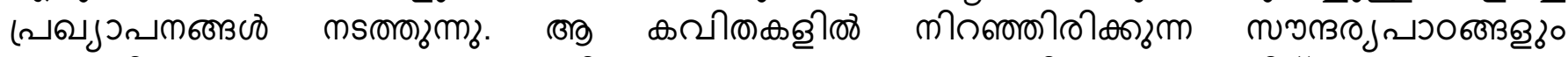

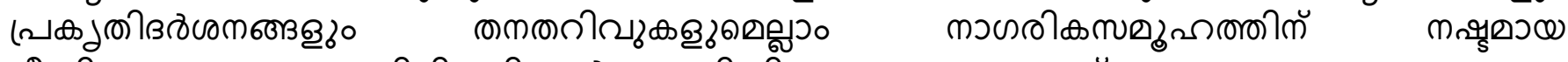

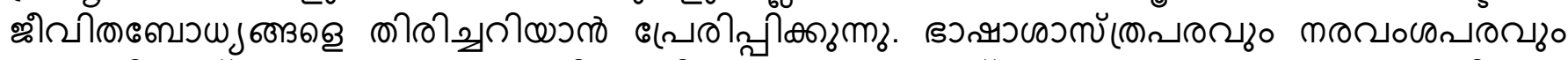

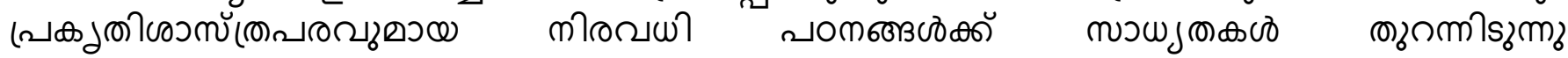

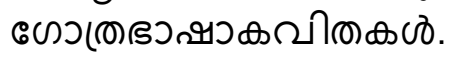

\section{References}

Chaligadha, S., Mavilan S.M., (2021). Tribal Poetry, Kottayam D C books, Kerala, India.

Velayudhan Pillai, P.V., (1998). Navodhana Samskaram Keralathil, Trivandrum, International Centre for Kerala Studies, University of Kerala, India.

Sreenadhan, M., (2006). Languages in Kerala, International Centre for Kerala Studies, University of Kerala, Trivandrum, India.

Marayur, A., (2019). Gree House, Kottayam DC books, Kerala, India.

Velappan, K., Bhashakalum, A.A., (1994). State Institute of Languages, Trivandrum, Kerala, India.

\section{Funding}

No funding was received for conducting this study. 
Does this article screened for similarity?

Yes

\section{Conflict of interest}

The Author has no conflicts of interest to declare that they are relevant to the content of this article.

\section{About the License}

(C) The author 2021. The text of this article is open access and licensed under a Creative Commons Attribution 4.0 International License

\section{Cite this Article}

R. Chandrabose, Aesthetics and Politics of Poetry written in Tribal Languages of Kerala, Indian Journal of Multilingual Research and Development, Vol 2, Iss 4 (2021) 25-38. DOI: https://doi.org/10.54392/ijmrd2144 